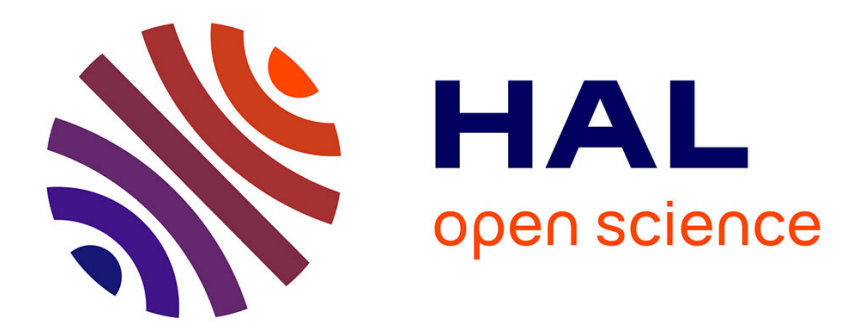

\title{
Liquidity Constraints, Fiscal Externalities and Optimal Tuition Subsidies
}

\author{
Nicholas Lawson
}

\section{To cite this version:}

Nicholas Lawson. Liquidity Constraints, Fiscal Externalities and Optimal Tuition Subsidies. 2014. halshs-00964527v2

\section{HAL Id: halshs-00964527 https://shs.hal.science/halshs-00964527v2}

Preprint submitted on 16 May 2014

HAL is a multi-disciplinary open access archive for the deposit and dissemination of scientific research documents, whether they are published or not. The documents may come from teaching and research institutions in France or abroad, or from public or private research centers.
L'archive ouverte pluridisciplinaire HAL, est destinée au dépôt et à la diffusion de documents scientifiques de niveau recherche, publiés ou non, émanant des établissements d'enseignement et de recherche français ou étrangers, des laboratoires publics ou privés. 


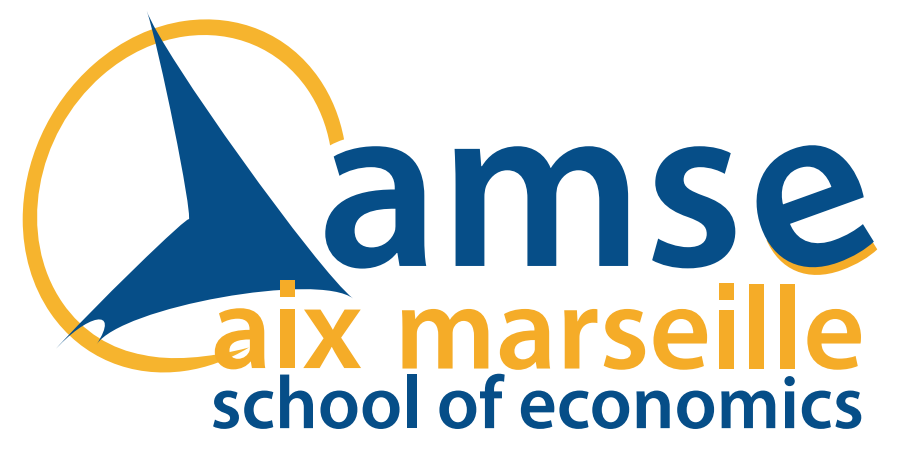

\section{Working Papers / Documents de travail}

\section{Liquidity Constraints, Fiscal Externalities and Optimal Tuition Subsidies}

Nicholas Lawson 


\title{
Liquidity Constraints, Fiscal Externalities and Optimal Tuition Subsidies
}

\author{
Nicholas Lawson* \\ Aix-Marseille University (Aix-Marseille School of Economics), CNRS \& EHESS \\ nicholas.lawson@univ-amu.fr
}

May 16, 2014

\begin{abstract}
A large body of theoretical and empirical research focuses on two very different rationales for government subsidies to college students: positive fiscal externalities from greater human capital accumulation and a larger income tax base, and the existence of liquidity constraints among student borrowers. This paper provides a first attempt to gauge the relative importance of these two mechanisms. I use two different modelling approaches, both of which use US data on the effects of income and tuition subsidies on college enrollment to discipline the analysis: calibration of a simple structural model of human capital accumulation, and a "sufficient statistics" approach that employs behavioral elasticities within a social welfare optimality condition. The results imply optimal subsidies that are quite large, of a magnitude similar to median tuition at public universities. This finding is almost entirely driven by the fiscal externality channel, indicating that optimal tuition subsidy policy is not sensitive to the extent of liquidity constraints among students.
\end{abstract}

Keywords: college tuition subsidies, fiscal externality, liquidity constraints, sufficient statistics

*I am very grateful to David Lee, Andrew Clark and Cecilia García-Peñalosa for many helpful comments and suggestions, and also to Raj Chetty, Jacob Goldin, Marc Sangnier, and Dean Spears for their comments. I also wish to thank the participants of seminars at Princeton University and Queen's University. Any errors or omissions are the responsibilty of the author. 


\section{Introduction}

The affordability of a college education and appropriate government education policy is an important and widely-studied subject. ${ }^{1}$ A large body of theoretical and empirical research focuses on two rationales for government subsidies to students: positive fiscal externalities from the higher income tax base that results when subsidies lead to greater human capital accumulation, and liquidity constraints in the market for student borrowing, leading to an inefficiently low level of human capital investment. In this paper, I evaluate their impact on optimal tuition subsidies, providing a first attempt to gauge the relative importance of these two mechanisms.

The economic intuition behind a fiscal externality is simple: greater educational attainment leads to higher wages and higher tax revenues, but individuals do not internalize the benefits of higher tax revenues when making decisions about investments in education; thus, a subsidy to education offsets the pre-existing tax distortion and can increase efficiency. In other words, in the presence of distortionary income taxes, the social return to education can be significantly higher than the private return. Simulations in Trostel (1993) show that proportional income taxation could have a significant negative effect on investment in human capital, and Trostel (2010) quantifies the fiscal benefits of college attainment, finding that net government spending on the average college graduate is negative, which suggests that subsidies aimed at increasing enrollment and graduation could have important fiscal benefits. $^{2}$

The other important rationale for tuition subsidies that is emphasized in the literature is that there may be significant imperfections in capital markets, so that students are unable or unwilling to borrow to pay for the efficient level of human capital, as discussed in Kane (1999). Liquidity constraints have indeed been the subject of a large empirical literature, which often aims to learn about liquidity constraints by attempting to estimate the causal impact of family income on enrollment. The existence and empirical relevance of liquidity constraints among students remains the subject of a persistent empirical controversy. Several papers

\footnotetext{
${ }^{1}$ See, for example, the surveys in Kane (2006) and McPherson and Schapiro (2006).

${ }^{2}$ Trostel finds that direct expenditures of about $\$ 71000$ (in present-value 2005 dollars) per degree are more than offset by savings of $\$ 56000$ from reduced expenditures on programs such as social assistance and corrections, and increased tax revenues amounting to $\$ 197000$. Similar findings for high school graduation are discussed in a New York Times editorial, Levin and Rouse (January 25, 2012), which points out that reducing dropouts from high school would pay for itself.
} 
find little evidence of constraints, including Cameron and Heckman (2001) and Cameron and Taber (2004), while others find evidence of positive effects of income on enrollment, most notably Belley and Lochner (2007) who indicate that income has become a much more important determinant of enrollment in recent decades, perhaps due to rising tuition and reductions in spending on Pell Grants. ${ }^{3}$

Each of these two literatures suggests a different perspective on the question of governmental financial support for college education. If fiscal externalities are important, subsidies for enrollment will internalize the positive fiscal externality generated by the acquisition of human capital, and the important task for future research will be to better understand the extent to which taxes distort schooling decisions in the first place. On the other hand, if liquidity constraints are the major inefficiency in the area of college education, the essential goal of policy is to overcome the failure of credit markets, and a particular emphasis should be placed on investigating new strategies to identify liquidity constraints in various settings, as well as studying the optimal mix of policies between subsidies and student loan programs. ${ }^{4}$

A small existing literature evaluates optimal tuition subsidies by focusing only on one of these motives. ${ }^{5}$ However, the only way to gauge the relative importance of these two phenomena is to embed them within a common conceptual framework that is disciplined by the same estimates of behavioral elasticities and other important empirical quantities from existing literatures and available data. This is precisely what I do in this paper, using two complementary approaches in which the parameters are chosen to ensure that the model matches the evidence on key features of the US education sector. ${ }^{6}$ I calculate optimal subsidies in a baseline case, and then I evaluate the relative importance of fiscal externalities

\footnotetext{
${ }^{3}$ Lochner and Monge-Naranjo (2011) and Lochner and Monge-Naranjo (2012) also argue that borrowing constraints, in particular those that are endogenous to student ability, have become increasingly important in recent years, whereas a series of additional papers summarized in Cunha, Heckman, Lochner, and Masterov (2006) argue that borrowing constraints are of limited importance.

${ }^{4}$ Keane and Wolpin (2001) and Johnson (2012) argue that raising borrowing limits in guaranteed loan programs will have very little effect on enrollment or graduation, because of a precautionary savings motive; Johnson (2012) argues that tuition subsidies will be much more effective than loans in raising college completion. As a result, as well as for simplicity, I abstract from changes in loan policy in my analysis, assuming a fixed borrowing constraint, and focus on grants to students, which can both offset fiscal externalities and loosen any borrowing constraints that may exist.

${ }^{5}$ Trostel (1996), Akyol and Athreya (2005), and Bohacek and Kapicka (2008) focus exclusively on fiscal externalities, while Caucutt and Kumar (2005) focus on liquidity constraints and ignore income taxes.

${ }^{6}$ The existing literature uses simulations of structural models for which the parameter values are selected in accordance with values used in related literatures rather than through a calibration to important moments of data from the education sector; for example, Akyol and Athreya (2005) choose parameters of a production function and individual income persistence process from the macro labour literature.
} 
and liquidity constraints by varying the strength of each channel and by isolating each channel one at a time.

The two approaches I use in my analysis are a "sufficient statistics" approach and the calibration of a parameterized structural model, approaches that have both been widely used in the extensive literature on optimal unemployment insurance. Using the sufficient statistics method, I derive an equation for the derivative of social welfare with respect to student grants as a function of a few empirical statistics, which are therefore the sufficient statistics for welfare analysis (see Chetty (2009) for a detailed discussion of the method). Specifically, the effect of income on enrollment, which depends on the magnitude of liquidity constraints, is weighed against the fiscal benefits of a larger tax base.

The sufficient statistics approach does not require that I specify the underlying structural parameters and functional forms; empirical measurement of the sufficient statistics is all that is needed to make welfare predictions. However, the welfare derivative is only valid locally, and in order to make out-of-sample predictions and solve for the optimal policy, a statistical extrapolation of the sufficient statistics is required. Such an extrapolation can be viewed as ad-hoc, and so I complement this analysis by using the sufficient statistics to calibrate and simulate a structural model, to demonstrate the robustness of my results to alternative assumptions.

Both approaches suggest relatively large optimal tuition subsidies. ${ }^{7}$ In the baseline case, the magnitude of the optimal subsidy is similar to median tuition at public universities. When I examine the relative importance of fiscal externalities and liquidity constraints, I find that the result is driven by the former: higher tuition subsidies lead to increased enrollment and a larger tax base, so that a relatively small tax increase is needed to pay for the increased subsidies. Liquidity constraints are of second-order importance for optimal subsidy policy: fiscal externalities on their own are sufficient to justify large increases in subsidies, and enacting such a generous policy would render any liquidity constraints largely irrelevant. This insensitivity of my results to liquidity constraints suggests that it may not be necessary to reach a consensus on the precise magnitude of liquidity constraints in order to make welfare statements about tuition subsidy policy.

Instead, my findings suggest that an important topic for future research is to provide

\footnotetext{
${ }^{7}$ This result is similar to the finding in Saez (2002) that an Earned Income Tax Credit is optimal when lowincome behavioural responses to taxation are concentrated on the extensive margin: the education decision is an important extensive margin, and thus a large transfer to individuals on that margin may be efficient.
} 
improved evidence on the size of externalities from education, and in the final section of this paper I explore the sensitivity of my results to general equilibrium effects of tuition subsidies on wages. Although my baseline partial equilibrium analysis is a natural starting point, given the controversy surrounding the existence and size of general equilibrium effects, ${ }^{8}$ the sensitivity analysis indicates that the optimal level of tuition subsidies would be sensitive to strong general equilibrium effects. If increased enrollment significantly reduces the college wage premium, then tuition subsidies will ultimately be unsuccessful at substantially increasing enrollment, whereas positive wage spillovers from the educated to other individuals could justify stipends to students of around $\$ 10000$ per year above and beyond the value of tuition. However, the main finding of the paper is robust to these extensions: liquidity constraints continue to have a small impact on optimal policy. These findings indicate that future study of the general equilibrium effects of education subsidies would be of great value to policy analysis.

The rest of the paper is organized as follows. Section 2 presents my model, and solves it for a sufficient statistics expression for the derivative of social welfare with respect to student grants. Section 3 provides the baseline numerical results for optimal tuition subsidies. Section 4 then performs the experiment of shutting down the liquidity constraint and fiscal externality motivations for financial aid one by one, to examine their relative importance. Section 5 extends the model to include general equilibrium effects, and section 6 provides a conclusion.

\section{A Simple Model of College Education}

In this section, I present my model of college education, followed by the calculations leading to an expression for the derivative of social welfare with respect to student grants. The model is intentionally simple and intuitive, to highlight the essential tradeoffs of financial aid policy. However, my results hold in a far more general analysis, as demonstrated in Lawson (2014), where I produce an expression that simplifies to exactly the same form. Additionally, to be conservative, I abstract away from non-monetary motivations for government support

\footnotetext{
${ }^{8}$ See, for example, the constrasting conclusions of Heckman, Lochner, and Taber (1998a) and Lee (2005) on the impact of college enrollment on relative wages, the hypothesis of Acemoglu (1998) on directed skillbiased technological change, and the disagreement of Moretti (2004b) and Ciccone and Peri (2006) on the existence of spillovers. Several of the papers in the existing numerical literature, specifically Trostel (1996) and Bohacek and Kapicka (2008), assume a partial equilibrium setting.
} 
of students, such as social benefits from better-educated citizens, as well as other potential positive externalities from education such as effects on growth; as these factors would tend to raise the optimal subsidy, they would even further weaken the relevance of liquidity constraints.

\subsection{Model Setup}

Time is finite, and is divided into two parts: in the first, each individual has a choice of attending college or working, while in the second, individuals work at wages which depend on their education level. Since the second part will be far longer than the first, the model will consist of 12 periods, 1 in the first part and 11 in the second, where each period corresponds to 4 years, thus representing a normal working life of 48 years (say, from age 18 to 65 inclusive). This is equivalent in practical terms to a two-period model, but since discounting and comparison of quantities across periods is of great importance in my analysis, the notation and intuition are both simplified when periods of equal length are used.

In the first period, the individual chooses between attending college and working at wage $Y_{01}$, and this choice is represented by $s=\{0,1\}$, where 1 indicates college attendance. In periods $t=2, \ldots, 12$, the individual works at a wage $Y_{s t}$ that depends on the education choice in the first period, where $Y_{1 t}>Y_{0 t} \cdot{ }^{9} \mathrm{I}$ assume that the real interest and discount rates are both equal to $r$, with the discount factor therefore equal to $\beta=\frac{1}{1+r}$, and I allow for wage growth at a rate of $g$ per period.

The individual's utility from consumption $c$ while in college is $u(c)$, whereas it is $v(c)$ while employed, allowing for direct utility or disutility from college attendance as well as different utility from consumption in the two states. Both utility functions obey the usual properties of $u^{\prime}, v^{\prime}>0$ and $u^{\prime \prime}, v^{\prime \prime}<0$, and I denote individuals by $i$. If an individual chooses not to attend college, then since the interest and discount rates are equal, they will simply set consumption to a constant value $c_{v i}^{0}$ in each period, and receive lifetime utility of $U_{0 i}=\sum_{t=1}^{12} \beta^{t-1} v\left(c_{v i}^{0}\right)$. If they do attend college, they will set per-period post-schooling consumption $c_{v i}^{1}$ to some constant value, and choose some value $c_{u i}$ of consumption while in school, receiving lifetime utility of $U_{1 i}+\eta_{i}$, where $U_{1 i}=u\left(c_{u i}\right)+\sum_{t=2}^{12} \beta^{t-1} v\left(c_{v i}^{1}\right)$ and where $\eta_{i}$ captures any idiosyncratic portion of the utility or disutility from schooling. ${ }^{10}$

\footnotetext{
${ }^{9}$ These wages are assumed to be exogenous, and there is no uncertainty. I allow for uncertainty in future incomes in an extension in appendix C.3.

${ }^{10}$ I therefore consider a "representative-agent" setting in which there is heterogeneity in taste for schooling
} 
The individual's budget constraints, for $s=0$ and $s=1$ respectively, can be written in the following way:

$$
\begin{gathered}
\sum_{t=1}^{12}\left(\frac{1}{1+r}\right)^{t-1} c_{v i}^{0}=(1-\tau) \sum_{t=1}^{12}\left(\frac{1}{1+r}\right)^{t-1} Y_{0 t} \\
c_{u i}+\sum_{t=2}^{12}\left(\frac{1}{1+r}\right)^{t-1} c_{v i}^{1}=(b-e)+(1-\tau) \sum_{t=2}^{12}\left(\frac{1}{1+r}\right)^{t-1} Y_{1 t}
\end{gathered}
$$

where $e$ is the direct cost of college to the individual, ${ }^{11} \tau$ is the marginal tax rate, and $b$ is the government grant given to students. For simplicity, I restrict attention to a lump-sum grant for now, though I will consider a 2-tier grant scheme in appendix C.4. ${ }^{12}$ To simplify the notation, let me define $R_{x}=\sum_{t=x}^{12}\left(\frac{1}{1+r}\right)^{t-1}$ and $\gamma_{x}=\sum_{t=x}^{12}\left(\frac{1+g}{1+r}\right)^{t-1}$; then the budget constraints can be written as:

$$
\begin{gathered}
R_{1} c_{v i}^{0}=(1-\tau) \gamma_{1} Y_{01} \\
c_{u i}+R_{2} c_{v i}^{1}=(b-e)+(1-\tau) \gamma_{2} Y_{11} .
\end{gathered}
$$

I also allow students to face a liquidity constraint, which will take the form of a limit $A_{i}$ to the debt that a student may accumulate:

$$
c_{u i}-(b-e) \leq A_{i}
$$

Given the lack of uncertainty in the labour market, this constraint will never bind on individuals who have completed their education.

Therefore, the individual's maximization problem is to choose $\left\{s_{i}, c_{v i}^{0}, c_{v i}^{1}, c_{u i}\right\}$ to maximize $V_{i}=s_{i}\left(U_{1 i}+\eta_{i}\right)+\left(1-s_{i}\right) U_{0 i}$ :

$$
\begin{gathered}
V_{i}=s_{i}\left[u\left(c_{u i}\right)+R_{2} v\left(c_{v i}^{1}\right)+\eta_{i}-\lambda_{1 i}\left(c_{u i}+R_{2} c_{v i}^{1}-(b-e)-(1-\tau) \gamma_{2} Y_{11}\right)-\mu_{i}\left(c_{u i}-(b-e)-A_{i}\right)\right] \\
+\left(1-s_{i}\right)\left[R_{1} v\left(c_{v i}^{0}\right)-\lambda_{0 i}\left(R_{1} c_{v i}^{0}-(1-\tau) \gamma_{1} Y_{01}\right)\right]
\end{gathered}
$$

The government chooses $b$ and $\tau$ subject to a budget constraint:

$$
S b+G=\tau\left[S \gamma_{2} Y_{11}+(1-S) \gamma_{1} Y_{01}\right]=\tau \bar{Y}
$$

but not income or returns to education; heterogeneity in the latter dimension is considered in appendix C.5.

${ }^{11}$ This cost is assumed to be exogenous and constant.

${ }^{12}$ Partly due to the rising importance of merit aid and tax credits, government financial aid is not universally directed at low-income families; McPherson and Schapiro (2006) state that governments provide "rather little" in the form of grants to low-income students. 
where $S=E\left(s_{i}\right)$ is the mean of $s_{i}$ across the population, or the fraction of the population attending college, $G$ is the discounted total of other (exogenous) government spending over the 12 periods, ${ }^{13}$ and $\bar{Y}$ is mean total discounted lifetime income. If $V_{i}$ is total lifetime utility of individual $i$, and social welfare $V$ is utilitarian with equal weights, then $V=E\left(V_{i}\right)$ and the social welfare gain from increasing the student grant $b$ is:

$$
\begin{aligned}
\frac{d V}{d b} & =\frac{\partial V}{\partial b}+\frac{\partial V}{\partial \tau} \frac{d \tau}{d b} \\
& =E\left(\frac{\partial V_{i}}{\partial b}\right)+E\left(\frac{\partial V_{i}}{\partial \tau}\right) \frac{d \tau}{d b}
\end{aligned}
$$

\subsection{Welfare Calculations}

I will now solve the model for an empirically-implementable version of (1). First, I evaluate the terms in (1), making use of the (unwritten) first-order conditions of the individual's maximization problem:

$$
\begin{gathered}
\frac{\partial V_{i}}{\partial b}=s_{i}\left(\lambda_{1 i}+\mu_{i}\right)=s_{i} u^{\prime}\left(c_{u i}\right) \\
\frac{\partial V_{i}}{\partial \tau}=-s_{i} \lambda_{1 i} \gamma_{2} Y_{11}-\left(1-s_{i}\right) \lambda_{0 i} \gamma_{1} Y_{01}=-s_{i} \gamma_{2} Y_{11} v^{\prime}\left(c_{v i}^{1}\right)-\left(1-s_{i}\right) \gamma_{1} Y_{01} v^{\prime}\left(c_{v i}^{0}\right) \\
\frac{d \tau}{d b}=\frac{S}{\bar{Y}}\left[1+\varepsilon_{S b}-\left(1+\frac{G}{S b}\right) \varepsilon_{\bar{Y} b}\right]
\end{gathered}
$$

where $\varepsilon_{a b}$ represents the (total derivative) elasticity of $a$ with respect to $b$, and thus $\varepsilon_{S b}$ measures the effect of student grants on college enrollment, while $\varepsilon_{\bar{Y} b}$ measures the total effect of grants on average income, and thus on the tax base. Defining $E_{0}[\cdot]$ and $E_{1}[\cdot]$ as expectations over individuals for whom $s_{i}=0$ and $s_{i}=1$ respectively, the welfare derivative is:

$\frac{d V}{d b}=S E_{1}\left[u^{\prime}\left(c_{u i}\right)\right]-\left[S \gamma_{2} Y_{11} E_{1}\left[v^{\prime}\left(c_{v i}^{1}\right)\right]+(1-S) \gamma_{1} Y_{01} E_{0}\left[v^{\prime}\left(c_{v i}^{0}\right)\right]\right] \frac{S}{\bar{Y}}\left[1+\varepsilon_{S b}-\left(1+\frac{G}{S b}\right) \varepsilon_{\bar{Y} b}\right]$.

Next, I use the fact that $\eta_{i}$, the idiosyncratic taste for schooling, only affects the choice of $s_{i}$, and that the debt limit has no effect on the consumption of those who do not attend college; therefore, $c_{v i}^{0}=c_{v}^{0}$ is constant across individuals and $E_{0}\left[v^{\prime}\left(c_{v i}^{0}\right)\right]=v^{\prime}\left(c_{v}^{0}\right)$. Next, for some intermediate value of consumption $c^{*}$, I can write $S \gamma_{2} Y_{11} E_{1}\left[v^{\prime}\left(c_{v i}^{1}\right)\right]+(1-S) \gamma_{1} Y_{01} v^{\prime}\left(c_{v}^{0}\right)=$ $\bar{Y} v^{\prime}\left(c^{*}\right)$; presumably $c_{v i}^{1}>c_{v}^{0}$, and therefore by the intermediate value theorem $c_{v i}^{1}>c^{*}>c_{v}^{0}$

\footnotetext{
${ }^{13}$ Because $G$ is exogenously fixed, I do not need to account for it in individual utility.
} 
and $v^{\prime}\left(c^{*}\right)<v^{\prime}\left(c_{v}^{0}\right)$. The expression for $\frac{d V}{d b}$ thus becomes:

$$
\frac{d V}{d b}=S E_{1}\left[u^{\prime}\left(c_{u i}\right)\right]-S v^{\prime}\left(c^{*}\right)\left[1+\varepsilon_{S b}-\left(1+\frac{G}{S b}\right) \varepsilon_{\bar{Y} b}\right] .
$$

Finally, I normalize the welfare gain into a dollar amount, to facilitate a comparison to the size of tuition subsidies and a simple expression of the economy-wide gain. Define $\frac{d W}{d b} \equiv \frac{\frac{d V}{d b}}{v^{\prime}\left(c_{v}^{0}\right)} ;$ this expresses the welfare gain in terms of an equivalent amount of additional consumption among non-graduates. Therefore:

$$
\begin{aligned}
\frac{d W}{d b} & =S \frac{E_{1}\left[u^{\prime}\left(c_{u i}\right)\right]}{v^{\prime}\left(c_{v}^{0}\right)}-S \frac{v^{\prime}\left(c^{*}\right)}{v^{\prime}\left(c_{v}^{0}\right)}\left[1+\varepsilon_{S b}-\left(1+\frac{G}{S b}\right) \varepsilon_{\bar{Y} b}\right] \\
& \simeq S\left[\frac{E_{1}\left[u^{\prime}\left(c_{u i}\right)\right]-v^{\prime}\left(c_{v}^{0}\right)}{v^{\prime}\left(c_{v}^{0}\right)}-\varepsilon_{S b}+\left(1+\frac{G}{S b}\right) \varepsilon_{\bar{Y} b}\right] .
\end{aligned}
$$

By making the assumption that $v^{\prime}\left(c^{*}\right) \simeq v^{\prime}\left(c_{v}^{0}\right)$ above, I am overstating the relative importance of the derivative of the government budget constraint $\frac{d \tau}{d b}$; given that the optimum must occur where $\frac{d \tau}{d b}$ is positive, this will lead to an underestimate of the optimal $b .{ }^{14}$

Equation (3) provides a simple and intuitive illustration of the welfare consequences of tuition subsidies in terms of the magnitudes of liquidity constraints and fiscal externalities. The first term in the square brackets, the ratio of marginal utilities, measures the welfare effect of taking a dollar from workers and giving it to students, which depends on the magnitude of liquidity constraints: if students are highly constrained, their marginal utility of income will be large and redistribution will generate welfare gains. Meanwhile, the remaining terms measure the fiscal impact of tuition subsidies: if higher subsidies raise average incomes, the resulting increase in tax revenues will also raise welfare.

Although this result is very general ${ }^{15}$ - I demonstrate in Lawson (2014) that a formula of this sort could be applied to any government transfer program - this model has been conspicuous in its simplicity, for two reasons: ease of interpretation, and a starting point for the next step in my analysis, which is the replacement of the ratio of marginal utilities with some empirically observable quantity. Similar to the analysis of unemployment insurance in Chetty (2008), I will decompose the marginal utility term into two effects, which I call liquidity and substitution effects. ${ }^{16}$

\footnotetext{
${ }^{14}$ When I produce results using a structural approach, I will no longer need to make this assumption.

${ }^{15}$ It applies unchanged, for example, to a setting in which there is a non-constant life-cycle profile of earnings; what matters is the direct redistributional gain and the effect of subsidies on $S$ and the tax base.

${ }^{16}$ Chetty (2008) refers to the latter as a moral hazard effect in the context of unemployment insurance.
} 
For simplicity, let me first assume that debt limits are the same for all individuals; the result is robust to a distribution of debt limits under certain assumptions, as I show in appendix $\mathrm{A}$ as well as in a sensitivity analysis in appendix C.4, but the intuition is clearer in the simplest case. Then, since the only heterogeneity enters in the form of the personal taste for schooling $\eta_{i}$, consumption choices if schooling is undertaken are identical for all individuals, i.e. $c_{u i}=c_{u}, c_{v i}^{1}=c_{v}^{1}$ for all $i$. An individual chooses to attend college if $U_{1}+\eta_{i} \geq U_{0}$, or equivalently if the taste for schooling exceeds a critical value $\eta^{*}$ :

$$
\eta^{*}=R_{1} v\left(c_{v}^{0}\right)-u\left(c_{u}\right)-R_{2} v\left(c_{v}^{1}\right)
$$

I assume that the taste for schooling $\eta_{i}$ follows some continuously differentiable distribution $F(\eta)$, with a density given by $f(\eta)$. It follows that $S=1-F\left[R_{1} v\left(c_{v}^{0}\right)-u\left(c_{u}\right)-R_{2} v\left(c_{v}^{1}\right)\right]$, and therefore:

$$
\begin{gathered}
\frac{\partial S}{\partial b}=f\left(\eta^{*}\right) u^{\prime}\left(c_{u}\right) \\
\frac{\partial S}{\partial a_{1}}=f\left(\eta^{*}\right)\left[u^{\prime}\left(c_{u}\right)-v^{\prime}\left(c_{v}^{0}\right)\right]
\end{gathered}
$$

where $a_{1}$ is an additional lump-sum of cash in the first period, representing changes in initial assets. It follows that I can rewrite (3) in the following way:

$$
\frac{d W}{d b} \simeq S\left[L-\varepsilon_{S b}+\left(1+\frac{G}{S b}\right) \varepsilon_{\bar{Y} b}\right]
$$

where $L=\frac{\frac{\partial S}{\partial a_{1}}}{\frac{\partial S}{\partial b}-\frac{\partial S}{\partial a_{1}}}$.

The $\frac{\partial S}{\partial a_{1}}$ in the numerator of $L$ is the liquidity effect, as it is the effect on enrollment of changing initial assets, whereas I call the $\frac{\partial S}{\partial b}-\frac{\partial S}{\partial a_{1}}$ in the denominator the substitution effect, as it represents the effect on enrollment of changing relative prices without providing immediate income to students. $L$ is therefore the liquidity-substitution ratio, and a higher value of $L$ indicates more severe liquidity constraints and a greater welfare gain from redistributing to students. ${ }^{17}$ (4) is the equation I will use in my sufficient statistics analysis in

\footnotetext{
${ }^{17}$ Notice that if there is no causal effect of income on enrollment, i.e. $\frac{\partial S}{\partial a_{1}}=0$, it must be that $u^{\prime}\left(c_{u}\right)=$ $v^{\prime}\left(c_{v}^{0}\right)$, and I expect that $v^{\prime}\left(c_{v}^{0}\right)>v^{\prime}\left(c_{v}^{1}\right)$, so therefore $u^{\prime}\left(c_{u}\right)>v^{\prime}\left(c_{v}^{1}\right)$. However, the absence of liquidity constraints requires $u^{\prime}\left(c_{u}\right)=v^{\prime}\left(c_{v}^{1}\right)$; therefore, a precisely-estimated zero effect of income on enrollment is in fact evidence in favour of liquidity constraints. If individuals were unconstrained, income should have a negative causal effect on enrollment, because a dollar of income would be more valuable to those who do not attend college, as argued by Belley and Lochner (2007). When I study a case without liquidity constraints in section 4.1, I find that the model implies that each additional $\$ 1000$ of initial assets should reduce enrollment by between 0.12 and 0.25 percentage points. Therefore, my results support the argument of Belley and Lochner (2007) that a zero causal effect of income on enrollment should not necessarily be taken as evidence against liquidity constraints.
} 
the next section, as it allows me to estimate the welfare gain from a marginal change in $b$, given values of the quantities which appear in the equation.

\section{$3 \quad$ Numerical Results}

In this section, I will focus on providing the baseline numerical results for optimal tuition subsidies, starting with equation (4). First of all, using estimates of the current values of each

of the sufficient statistics in (4), I calculate an estimated value of $\frac{d W}{d b}$ and thereby determine if financial aid ought to be increased or decreased. To go beyond this local derivative, I must make additional assumptions, and I begin by performing statistical extrapolations of the quantities in (4), predicting their values out of sample. As an alternative, I then use the sufficient statistics to calibrate my model and simulate to find the optimum, to demonstrate that similar results can be obtained from both methods.

\subsection{Sufficient Statistics Method}

To evaluate (4), I must specify values for a number of quantities; these values are summarized in Table 1. Throughout the numerical analysis, I use estimates derived from American data. To begin with, I use $S=0.388$, which is the estimated enrollment rate of 18-24-year-olds in 2007 from NCES (2011). ${ }^{18}$ I also specify a baseline grant of $b=2$ (defining monetary amounts as thousands of dollars per year), using data on federal aid and state grants in 2007-08 from NCES (2011) and applying the formula of Epple, Romano, and Sieg (2006) for turning loans and work-study into grant equivalents. ${ }^{19}$

In choosing $b=2$, I am assuming that the out-of-pocket tuition cost $e$ prior to government aid covers the marginal cost of college education. At public institutions, this may not be accurate if colleges' need for public funding increases with enrollment, but increased education should also lead to reductions in government spending on programs such as corrections, social insurance and social assistance. In fact, Trostel (2010) finds that additional expen-

\footnotetext{
${ }^{18}$ This value is a compromise between the proportion of individuals ever enrolled (Lovenheim (2011) finds that $52 \%$ of his sample has completed more than 12 years of schooling) and the proportion actually completing a degree, which was $28.7 \%$ in 2007 according to NCES (2011).

${ }^{19}$ In 2007-08, 27.6\% of undergraduates received federal grants averaging $\$ 2800,34.7 \%$ received federal loans averaging $\$ 5100,5.6 \%$ received federal work-study averaging $\$ 2300$, and $16.4 \%$ received state grants averaging \$2500; Epple, Romano, and Sieg (2006) suggest using a formula of aid $=$ grants $+0.25 \times$ loans + $0.5 \times$ workstudy, which gives a per-person average of $\$ 1690$. Lacking data on other government aid and tax credits, I round this total up to $\$ 2000$.
} 
ditures on appropriations per degree are roughly offset by reductions in other government spending, ${ }^{20}$ supporting my assumption that the marginal cost of education is well captured by $e$; in that case, increased education appropriations and reduced social spending cancel out of the government budget constraint and I can ignore both in my analysis. My conclusions, however, are not sensitive to this assumption, as the effects of education on other program expenditures are dwarfed by the effect on income; in appendix C.2, I redo all the calculations using Trostel's most pessimistic estimates, and the results are only slightly changed.

Deming and Dynarski (2009) summarize the literature on the price response of college attendance, and conclude that the general consensus is that a $\$ 1000$ increase in price leads to a 4 percentage point decline in attendance, with a similar proportional impact on completion; this implies an elasticity of $\varepsilon_{S b} \simeq 0.2$, which will be my baseline case. However, Dynarski (2008) estimates that $\$ 2500$ of financial aid leads to a 4 percentage point increase in degree completion from a base of $27 \%$, which suggests a value closer to 0.1 , so I will present results for this case as well.

As discussed in the introduction, numerous papers argue that income has no causal effect on enrollment, so $L=0$ will be my preferred estimate. However, several papers do find a positive income effect; results in Acemoglu and Pischke (2001) imply that a $\$ 1000$ increase in family income increases enrollment by $0.21 \%$ points. ${ }^{21}$ Therefore, I will also produce results using $\frac{\partial S}{\partial a_{1}}=0.0021$, which implies $L=0.057$ or 0.121 depending on the value of $\varepsilon_{S b},{ }^{22}$ the comparison to $L=0$ will provide a first test of the relevance of liquidity constraints to optimal policy.

I assume that the interest and discount rates are $3 \%$ per year, and since a period is equal to 4 years, I will use $r=0.12$ for the interest rate and $\beta=\frac{1}{1.12} \simeq 0.893$ for the discount

\footnotetext{
${ }^{20}$ Trostel (2010) liberally estimates the cost to government per degree at $\$ 71400$ in present value, or about $\$ 16000$ per year of education beyond direct subsidies; meanwhile, he conservatively estimates the reduction in expenditures on such things as Medicaid, UI, and corrections per degree as $\$ 55800$ in present value, or about $\$ 14000$ per year. Of course, the cost of the marginal degree is not the same thing as the cost of a marginal increase in tuition subsidies, as the latter must also be paid to inframarginal students.

${ }^{21}$ Acemoglu and Pischke (2001) find that a $10 \%$ increase in income raises enrollment by $1.4 \%$ points; I report results in terms of 2007 dollars. Meanwhile, Belley and Lochner (2007) find that the income difference between the first and fourth quartiles of family income can explain $16 \%$ points of difference in enrollment, which implies that $\$ 1000$ in income raises enrollment by $0.15 \%$ points. Using Canadian data, Coelli (2011) finds an estimated effect of $1 \%$ point of enrollment per $\$ 1000$ of income, but his variation in income comes from parental job loss, which is unlikely to be uncorrelated with enrollment through other channels. Furthermore, Coelli's estimate is implausibly large, implying that the $\$ 87000$ difference in income between top and bottom quartiles in Belley and Lochner (2007) can explain over 200\% of the actual difference in enrollment between those groups.

${ }^{22}$ To make this approximation, I assume that $\varepsilon_{S b}$ is equivalent to the partial derivative elasticity.
} 
factor. For real wage growth, I use the average net compensation series used by the Social Security Administration for the computation of the national average wage index, deflated using the CPI; the average real growth rate over 1991-2008 is almost exactly 1\%, so I allow wages to grow at $g=0.04$ per period.

For $\frac{G}{S b}$, the ratio of the exogenous government spending to spending on grants, I begin with my estimates of $b=2$ and $S=0.388$; I then need to estimate $\tau \bar{Y}$ in order to be able to compute $G$. I use a value of $\tau=0.23$, which incorporates a $15 \%$ federal tax rate, a $5 \%$ state tax, and 3\% for the Medicare tax. For $\bar{Y}$, the CPS 2008 Annual Social and Economic Supplement estimates the mean earnings of a high school graduate in 2007 to be $\$ 33609$, which I round up to $Y_{01}=34$, meaning that $Y_{11}=34(1.08)^{4}=46.26$ and $\bar{Y}=301.661$. Therefore, $G=68.606$, and the ratio of $G$ to grant spending is $\frac{G}{S b}=88.410$.

Finally, to calculate a value for the elasticity of income with respect to grants, I assume that each year of schooling increases earnings by a constant $8 \%,{ }^{23}$ and that the elasticity of taxable income to the net-of-tax rate is 0.4, as found by Gruber and Saez (2002). ${ }^{24}$ Utilizing these estimates, appendix B demonstrates that the elasticity is:

$\varepsilon_{\bar{Y} b}=\left[\frac{\left[\gamma_{2}(1.08)^{4}-\gamma_{1}\right] S}{\gamma_{2}(1.08)^{4} S+\gamma_{1}(1-S)}-\frac{0.4 \tau}{1-\tau}\left(1+\frac{G}{S b}\right)^{-1}\right] \frac{1-\tau}{1-1.4 \tau} \varepsilon_{S b}-\frac{0.4 \tau}{1-1.4 \tau}\left(1+\frac{G}{S b}\right)^{-1}$.

Therefore, $\varepsilon_{\bar{Y} b}$ takes a value of either 0.0142 or 0.0063 , depending on the value of $\varepsilon_{S b}$.

Table 1: Baseline Values of Sufficient Statistics

\begin{tabular}{ccc}
\hline \hline Statistic & Definition & Value \\
\hline$S$ & enrollment rate & 0.388 \\
$b$ & per-year student grant & 2 \\
$\varepsilon_{S b}$ & elasticity of enrollment w.r.t. $b$ & $\{0.1,0.2\}$ \\
$\frac{\partial S}{\partial a_{1}}$ & effect of income on enrollment & 0.0021 \\
$r$ & interest and discount rate per period & 0.12 \\
$\frac{G}{S b}$ & ratio of exogenous spending to grant spending & 88.410 \\
$\varepsilon_{\bar{Y} b}$ & elasticity of mean income w.r.t. $b$ & $\{0.0063,0.0142\}$ \\
\hline
\end{tabular}

\footnotetext{
${ }^{23}$ The bulk of the estimates summarized in Card (1999) are between $6 \%$ and $11 \%$, but more recent estimates are higher; see the summary in Dynarski (2008). Heckman, Lochner, and Todd (2006) and Carneiro, Heckman, and Vytlacil (2010) estimate "policy relevant treatment effects" of tuition subsidies that range from $9 \%$ to $25 \%$, suggesting that $8 \%$ is a conservative estimate.

${ }^{24}$ I adjust equilibrium earnings for changes in taxes according to this elasticity, but I do not directly model the labour supply decision; in this way, I will tend to produce an underestimate of the optimal $b$, since I overstate the cost of tax increases by ignoring increases in leisure.
} 
Plugging in each of these values, I find values for $\frac{d W}{d b}$ as displayed in Panel A of Table 2. They are positive and substantial, suggesting that a one dollar per year increase in student grants from the baseline of $\$ 2000$ would provide a welfare increase equivalent to between 18 and 44 cents per person per year for 4 years. Spreading the gains out over an entire lifetime and aggregating up to an economy-wide level, this means that a $1 \%$ increase in $b$ to $\$ 2020$ would provide a net welfare gain of $\$ 101$ to $\$ 245$ million per year for an increase in yearly grant spending of about $\$ 126$ million, ${ }^{25}$ indicating a very large return to public investments in education, as the fiscal benefits of subsidizing college education are substantial even if gains from redistribution to constrained individuals are zero.

Table 2: Results from Sufficient Statistics and Extrapolation using (4)

\begin{tabular}{lcc}
\hline \hline & \multicolumn{2}{c}{$\frac{\hat{\partial S}}{\partial a_{1}}$} \\
\cline { 2 - 3 }$\varepsilon_{S b}$ & 0 & 0.0021 \\
\hline & A. Estimate of $\frac{d W}{d b}$ at $b=2$ \\
\cline { 2 - 3 } 0.1 & 0.1811 & 0.2282 \\
& 0.4148 & 0.4370 \\
\cline { 2 - 3 } 0.1 & $\$ 5843$ & B. Optimal Student Grants \\
0.2 & $\$ 8093$ & $\$ 8371$ \\
\cline { 2 - 3 } 0.1 & C. Welfare Gains from Moving to Optimum \\
\cline { 2 - 3 } 0.2 & $\$ 947(30.5 \%)$ & $\$ 1750(56.4 \%)$ \\
\hline Panel A presents the one-period per-year increase in welfare, expressed \\
in dollars of consumption from a per-year one dollar increase in $b$. \\
Panel C expresses welfare gains as a one-time lump-sum increase in \\
consumption, and as a percentage of baseline spending on student grants. \\
This format is used throughout all subsequent tables of this form.
\end{tabular}

\subsection{Statistical Extrapolation}

To make predictions out of sample, and thereby to produce an estimate of the optimal level of student grants, I need to make some functional form assumptions. In the current subsection, I make functional form assumptions about the sufficient statistics themselves; this approach is proposed in Chetty (2009), and has previously been used in sufficient statistic studies of unemployment insurance, including Baily (1978) and Lawson (2013).

\footnotetext{
${ }^{25}$ I use the Census Bureau's April 2010 estimate of the 18-64 population as 194,296,087.
} 
First, let me now denote the baseline values of quantities using hats, i.e. $\hat{b}=2$ and $\hat{S}=$ 0.388. I assume a constant elasticity of enrollment with respect to grants, $\varepsilon_{S b}=\{0.1,0.2\}$, implying that $S=\phi b^{\varepsilon_{S b}}$, where $\phi=\frac{\hat{S}}{\hat{b}^{\varepsilon} S b}$. I can then write the government spending ratio as $\frac{G}{S b}=88.41 \frac{\hat{S} \hat{b}}{S b}$, and $\varepsilon_{\bar{Y} b}$ is given by (5) as before but with $\tau$ held fixed at 0.23 for simplicity.

This leaves only the liquidity-substitution ratio $L$ to be extrapolated. Belley, Frenette, and Lochner (2011) find that 16\% points of the gap in attendance at 4-year colleges between the highest and lowest family income quartiles is explained by income, so I follow their simple approach and assume that a 16 percentage point increase in enrollment is needed to reduce $L$ to zero. I assume that the effect of income on enrollment (as a fraction of the effect of $b$ on enrollment) declines linearly in enrollment until it reaches zero; therefore, given an initial $\hat{L}$, I assume $\frac{\partial S}{\partial a_{1}}=\frac{\hat{L}}{\hat{L}+1} \frac{0.16-(S-\hat{S})}{0.16} \frac{\partial S}{\partial b}$. Then, plugging this equation into $L=\frac{\frac{\partial S}{\partial a_{1}}}{\frac{\partial S}{\partial b}-\frac{\partial S}{\partial a_{1}}}$, I find that $L=\max \left\{\frac{\hat{L}(0.16-(S-\hat{S}))}{0.16+\hat{L}(S-\hat{S})}, 0\right\}$.

Putting all of this together, I obtain the results displayed in Panels B and C of Table 2; to estimate the net welfare gain from moving to the optimum, I numerically integrate $\frac{d W}{d b}$ from $b=2$ to the optimum. I then express the welfare gain in two ways: I multiply by 4 to calculate the dollar amount of an equivalent one-year per-person consumption increase, and I also divide by $\hat{S} \hat{b}$ to express the gain as a percentage of the initial size of the student grant program; the latter values are shown in brackets in Panel C.

The results indicate that student grants should be increased substantially, by at least $\$ 3800$ per year. NCES (2011) estimates that median tuition at public 4-year universities was $\$ 5689$ in 2007-08, so my results could be interpreted to mean that net tuition should be eliminated, and government appropriations increased accordingly. ${ }^{26}$ With a larger responsiveness of enrollment to tuition or more serious borrowing constraints, optimal grants are even larger, though the large optimal subsidy with low $\varepsilon_{S b}$ and positive $\frac{\partial S}{\partial a_{1}}$ should be taken with a grain of salt as it is due to the assumption that the liquidity constraint is loosened very slowly. With the preferred estimates of $\varepsilon_{S b}=0.2$ and $\frac{\hat{\partial S}}{\partial a_{1}}=0$, the optimal stipend is about $\$ 2400$ per year above and beyond the value of tuition. Meanwhile, the estimated welfare gains are substantial, particularly in comparison to the size of the policy change; aggregated

\footnotetext{
${ }^{26}$ Although this is outside the scope of the current analysis, a policy of abolishing tuition may be more effective than offsetting tuition with financial aid, for reasons of salience and reduced administration. Courant, McPherson, and Resch (2006) argue that the "old tradition of making public higher education 'free' has much to recommend it," and claim that this policy might be efficient if enrollment is sufficiently sensitive to tuition, but they do not evaluate the welfare implications of the policy themselves.
} 
to an economy-wide level, they indicate annual net welfare improvements of between $\$ 6.6$ billion and $\$ 24.3$ billion, or as much as $0.17 \%$ of GDP.

Additionally, the results indicate that, at least with the standard assumption of $\varepsilon_{S b}=0.2$,

liquidity constraints have a very small impact on the optimal subsidy: a shift from $\frac{\partial S}{\partial a_{1}}=0$ to the estimate from Acemoglu and Pischke (2001), described in that paper as a "large effect," raises the optimal subsidy by less than $\$ 300$, which is second-order next to the large increase in subsidies indicated in the baseline case.

The results for optimal subsidies are considerably larger than those found in the existing literature, with estimated optimal subsidy rates of about $40 \%$ of the total cost of education in Trostel (1996), 25-80\% in Akyol and Athreya (2005), around 70\% in Caucutt and Kumar (2005), and 0-20\% in Bohacek and Kapicka (2008). These differences are due to variation in assumptions: Trostel (1996) and Akyol and Athreya (2005) choose parameters which imply that enrollment is relatively unresponsive to subsidy rates, to an extent that appears to be at odds with empirical findings on the subject (however, Akyol and Athreya (2005) use a general equilibrium model). Meanwhile, Caucutt and Kumar (2005) abstract from fiscal externalities, and Bohacek and Kapicka (2008) use a model in which there are no direct costs of education and specify the "subsidy rate" as a reduction in taxes for a one-unit increase in education, making it difficult to translate their results into the usual framework. ${ }^{27}$

\subsection{Simulation of Calibrated Model}

As mentioned in the introduction, previous welfare analyses of college tuition subsidies have relied on simulations of parameterized structural models; the previous subsection therefore represents the first application of the method of extrapolation of sufficient statistics to the search for optimal subsidies. In this subsection, I will demonstrate that the results above are not an artifact of the method, by calculating optimal subsidies from a calibrated version of my simple structural model. However, unlike previous analyses, I will calibrate the model parameters using the sufficient statistics, to ensure that the moments of the model match

\footnotetext{
${ }^{27}$ A theoretical literature also studies the question of optimal tuition subsidies: Bovenberg and Jacobs (2005) present a model in which it is optimal for the subsidy rate on investments in education to equal the tax rate, returning human capital investment to the first-best amount, and numerous recent papers (including Richter (2009), Richter and Braun (2010), and Braun (2010)) qualify this finding by seeking conditions under which the quantity of education should be induced to move above or below the first-best amount. Braun (2010) argues that a subsidy rate greater than the tax rate will be optimal if the elasticity of human capital accumulation is increasing in educational investments, which is the case in my model, at least at an aggregate level.
} 
the most important empirical quantities in the education sector.

I begin by assuming CRRA utility, so $u(c)=\frac{c^{1-\theta}}{1-\theta}$ and $v(c)=\frac{c^{1-\rho}}{1-\rho}$. I specify starting incomes as $Y_{01}=34 y$ and $Y_{11}=34(1.08)^{4} y$, where $y=\alpha(1-\tau)^{E T I}$ and $\alpha=\frac{1}{(1-\hat{\tau})^{E T I}}$, so $y=1$ at baseline and shifts with $\tau$ to capture the distortionary effects of taxation. I also assume that $\eta$ follows a logistic distribution with mean $\mu$ and scale parameter $\sigma{ }^{28}$

I use $e=5.7$ to represent public tuition, and exogenous spending $G=68.606$ as described earlier. I assume that all individuals face the same $\operatorname{debt}$ limit $A$, so I have to solve for 5 parameters: $\{A, \theta, \rho, \mu, \sigma\}$. However, I only have three sufficient statistic conditions: $\hat{S}=$ $0.388, \varepsilon_{S b}=\{0.1,0.2\}$ and $\frac{\hat{\partial S}}{\partial a_{1}}=\{0,0.0021\}$, so I need to incorporate additional data.

One piece of data I can use is some comparison of the values of consumption: $\hat{c_{u}}, \hat{c_{v}^{0}}$ and $\hat{c}_{v}^{1}$. Any ratio of two of these, along with the equation for the debt limit and the first-order conditions, will define all three. One possibility is to use consumption values from the Consumer Expenditure Survey, where I find that, on average, college graduates consumed $73.9 \%$ of their pre-tax income and high school graduates consumed $83.4 \%$ in 2007 . The NBER's TAXSIM calculator for 2007 allows me to transform these into percentages of after-tax income (ignoring state taxes and assuming a single-earner married couple), and if I then apply those values to my estimates of $Y_{01}$ and $Y_{11}$, I find that consumption of college graduates is $27.58 \%$ higher than that of high school graduates: $\hat{c_{v}^{1}}=1.2758 \hat{c_{v}^{0}}$. An alternative is to use results in Keane and Wolpin (2001) implying student consumption (not including room and board) of $\$ 8077$ in 1987, plus the estimate from NCES (2011) of average room and board expenses in 1987-88 of $\$ 3037$, compared to average per-equivalent-person consumption of $\$ 15816$ in 1988 as estimated by Cutler and Katz (1991). I then find that student consumption is $73.18 \%$ of average consumption across a steady-state of individuals, which implies $\hat{c}_{v}^{1}=1.2437 \hat{c}_{v}^{0}$. These estimates are very similar, and so I will take a value halfway in between, specifically $\hat{c_{v}^{1}}=1.26 \hat{c_{v}^{0}}$.

Finally, I can use an external estimate of relative risk-aversion to pin down one of $\theta$ and $\rho$. A CRRA parameter of 1 is typical, so I assume $v(c)=\ln (c)$, but I also try $\rho=2$ in appendix C.1 and show that the results are not very sensitive to this alteration.

My calibration method begins by using $\hat{c}_{v}^{1}=1.26 \hat{c}_{v}^{0}$ to solve for the debt limit $A$; the condition $u^{\prime}\left(c_{u}\right)=(\hat{L}+1) v^{\prime}\left(c_{v}^{0}\right)$ then allows me to solve for $\theta$, and I can use these results and

\footnotetext{
${ }^{28} \mu$ is not normalized to zero because $u(c)$ and $v(c)$ both have zero intercepts, so $\mu$ represents the difference in intercepts, or the mean direct utility or disutility from schooling.
} 
the conditions that $\hat{S}=0.388$ and $\varepsilon_{S b}=\{0.1,0.2\}$ to find the parameters of the preference distribution, $\mu$ and $\sigma$. I then simulate the model for various values of $b$ to find the optimum, and the results are displayed in Table 3.

Table 3: Results from Calibration and Simulation

\begin{tabular}{ccc}
\hline \hline & \multicolumn{2}{c}{$\frac{\hat{\partial S}}{\partial a_{1}}$} \\
\cline { 2 - 3 }$\varepsilon_{S b}$ & 0 & 0.0021 \\
\hline & A. Numerical Estimate of $\frac{d W}{d b}$ at $b=2$ \\
\cline { 2 - 3 } 0.1 & 0.1246 & 0.1716 \\
0.2 & 0.4210 & 0.4432 \\
\cline { 2 - 3 } 0.1 & \multicolumn{2}{c}{ B. Optimal Student Grants } \\
\cline { 2 - 3 } 0.2 & $\$ 6151$ & $\$ 4848$ \\
& C. Welfare Gains from Moving to Optimum \\
\cline { 2 - 3 } 0.1 & $\$ 500(16.1 \%)$ & $\$ 970(31.2 \%)$ \\
0.2 & $\$ 3538(114.0 \%)$ & $\$ 3984(128.3 \%)$ \\
\hline
\end{tabular}

The results for the optimal level of $b$ are somewhat smaller than those in Table 2, by less than $\$ 2000$ except for a larger drop in the case where $\varepsilon_{S b}=0.1$ and $\frac{\hat{\partial S}}{\partial a_{1}}=0.0021$, in which my statistical extrapolations implied that the liquidity ratio goes to zero unrealistically slowly. The higher estimates in Table 2 are primarily the result of the statistical extrapolation of $L$, where I assumed that $L$ does not drop below zero; in simulations of the model, $L$ can drop below -0.2 at high values of $b$. However, the qualitative conclusions are similar, in that raising the tuition subsidy to offset median public tuition remains the optimal policy with $\varepsilon_{S b}=0.2$, and in the latter case the estimated welfare gains are actually larger than before, reaching $\$ 24.8$ billion in the baseline case; ${ }^{29}$ overall, they vary from a low of $\$ 3.5$ billion to a high of $\$ 27.9$ billion or $0.19 \%$ of GDP. And the impact of liquidity constraints is again modest: even substantial variation in $\frac{\partial S}{\partial a_{1}}$ does not alter the conclusion of greatly increased generosity of tuition subsidies.

Figure 1 displays the values of the enrollment rate $S$ over the relevant range for $\frac{\hat{\partial S}}{\partial a_{1}}=0$ (the results are almost identical for positive $\frac{\partial S}{\partial a_{1}}$ ). In both cases, but especially with $\varepsilon_{S b}=0.2$, the optimal policy (indicated by the squares) involves inducing significant increases in the fraction of the population that attends college. Figure 2 displays the budget-balancing tax rates, and it is remarkable (though hard to see) that, when $\varepsilon_{S b}=0.2$, a small increase in $b$

\footnotetext{
${ }^{29}$ This occurs both because $S$ rises faster with $b$ in the calibration case and because I no longer make the assumption implicit in equation (3) which overstates the importance of $\frac{d \tau}{d b}$.
} 
from the current level leads to a lower tax rate, because average income increases enough that the increased grants more than pay for themselves. This quickly ceases to be true as grants increase further, but if this standard estimate of the responsiveness of enrollment to tuition is correct, then at present we are slightly on the wrong side of a "financial aid Laffer curve," and thus there are Pareto improvements available from a small increase in tuition subsidies: taxes do not have to rise until the grant level reaches about $\$ 2570$. Beyond that, the tax rate does rise, which means that there is redistribution away from high school graduates, which is socially costly, and yet the losses of high school graduates are more than offset by the considerable gains of college graduates until $b$ is over $\$ 6000$.

Figure 1: Enrollment Rates as Function of $b$ for $\frac{\hat{\partial S}}{\partial a_{1}}=0$

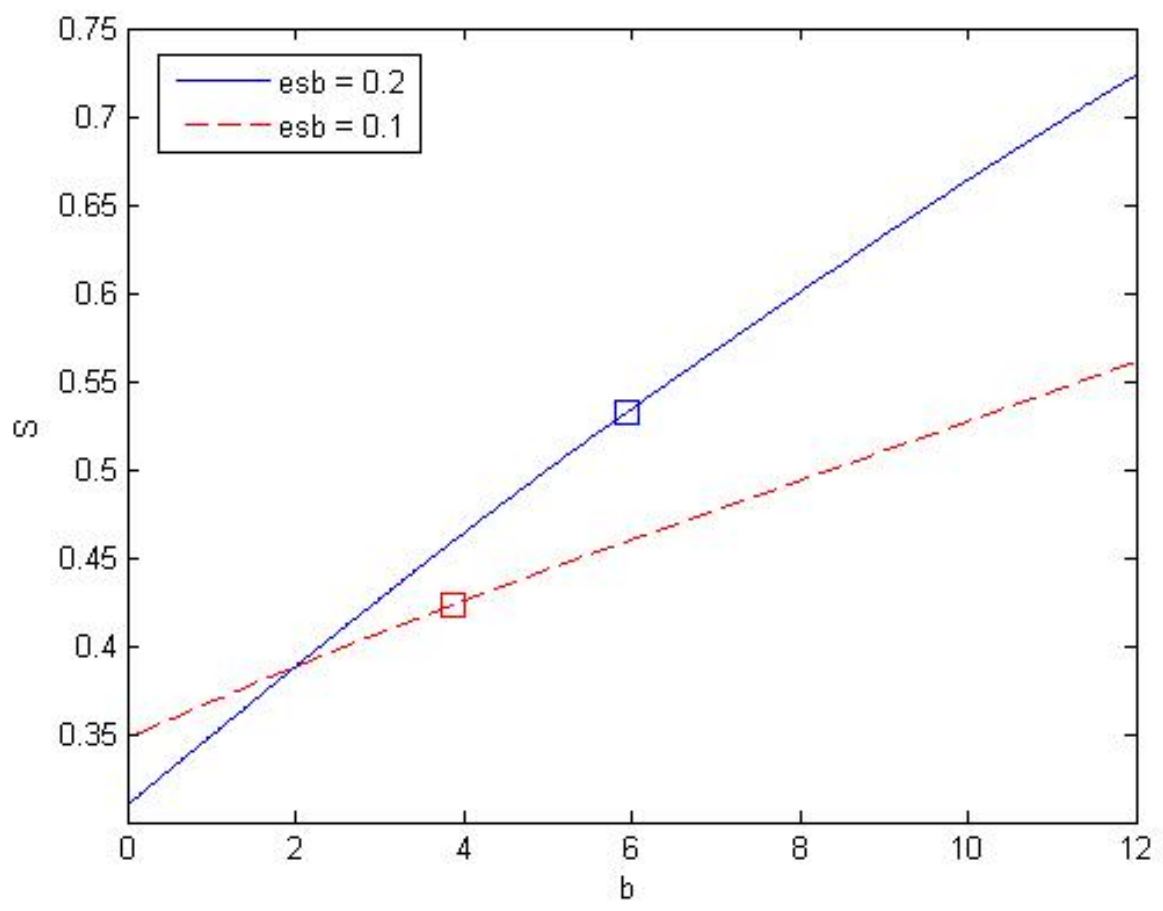

To further test the robustness of my results, I perform several extensions and alterations to the model in appendix C. A higher degree of risk-aversion slightly lowers optimal grants, while uncertainty about future income raises them; an alternative specification of government spending has varying effects depending on whether the statistical extrapolation or calibration method is used. I also find that heterogeneity in liquidity constraints has small effects on the results, while heterogeneous returns to education may lead to somewhat lower optimal subsidies but considerably larger welfare gains. The qualitative conclusions, however, are 
Figure 2: Budget-Balancing Tax Rate as Function of $b$ for $\frac{\hat{\partial S}}{\partial a_{1}}=0$

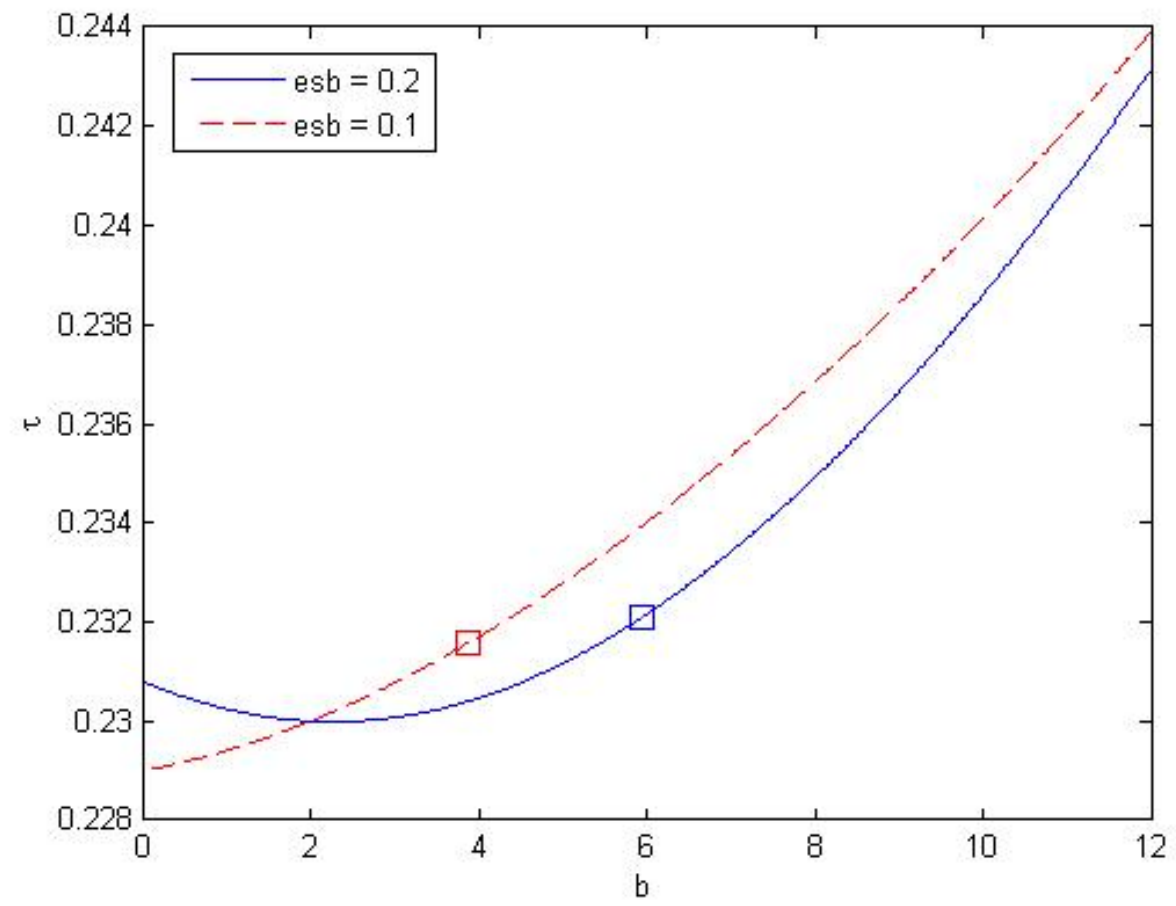

very similar across all extensions, and correspond closely to those found in this section.

\section{The Relative Importance of Liquidity Constraints and Fiscal Externalities}

In this section, I undertake a further analysis of the relative importance of liquidity constraints and fiscal externalities, as I perform the experiment of "switching off" the liquidity constraints and the fiscal externalities one at a time. As suggested by the results in the previous section, liquidity constraints have a relatively small impact on optimal subsidies, and eliminating all liquidity constraints does not greatly alter the results; in fact, it is even possible for the optimal subsidy to increase. However, eliminating the fiscal externality channel leads to a large reduction in optimal subsidies.

\subsection{No Liquidity Constraints}

I begin by assuming away liquidity constraints. This is difficult to accomplish within the sufficient statistics approach, as there is no simple way to impose a zero-liquidity-constraint 
condition; as noted in footnote $17, L=0$ does not correspond to no liquidity constraints, since an absence of liquidity constraints actually requires $v^{\prime}\left(c_{v}^{1}\right)=u^{\prime}\left(c_{u}\right)$, which implies a negative effect of income on enrollment. In order to impose the theoretical condition of no liquidity constraints in the sufficient statistics approach, I would need to know what empirical value of $L$ this would correspond to, and we cannot be sure that any existing estimate actually measures $\frac{\partial S}{\partial a_{1}}$ in a no-liquidity-constraint world.

Therefore, I focus on the structural analysis. I begin by using $\hat{c_{v}^{1}}=1.26 \hat{c_{v}^{0}}$ to solve for values of consumption, and then I use $v^{\prime}\left(c_{v}^{1}\right)=u^{\prime}\left(c_{u}\right)$, the no-liquidity-constraint condition, to solve for $\theta$. The rest of the calibration procedure continues as before, and the results are displayed in Table 4. The results are similar to before: the values of $\frac{d W}{d b}$ are somewhat smaller than in Table 3, but in the baseline case the welfare gain is nearly identical and the optimal benefit level is actually higher than in the $\frac{\partial \hat{S}}{\partial a_{1}}=0$ case, as the responsiveness of enrollment to subsidies is now driven entirely by the compactness of the distribution of $\eta$, rather than by liquidity constraints that diminish quickly as $b$ increases. This supports the evidence from the results in the previous section, demonstrating that my overall conclusion is not sensitive to the existence of liquidity constraints.

Table 4: Results from Calibration and Simulation with No Liquidity Constraints

\begin{tabular}{cc}
\hline \hline$\varepsilon_{S b}$ & \\
\hline & A. Numerical Estimate of $\frac{d W}{d b}$ at $b=2$ \\
\cline { 2 - 2 } 0.1 & 0.0451 \\
0.2 & 0.3412 \\
\cline { 2 - 2 } 0.1 & $\$ 3314$ \\
\cline { 2 - 2 } 0.2 & $\$ 6635$ \\
\cline { 2 - 2 } 0.1 & C. Welfare Gains from Moving to Optimum \\
\cline { 2 - 2 } 0.2 & $\$ 120(3.9 \%)$ \\
\hline
\end{tabular}

\subsection{No Fiscal Externalities}

Next, I instead shut off the fiscal externality, in the sense that I ignore $G$ and assume that $\tau_{t}$ is a lump-sum tax imposed on employed workers to pay for tuition subsidies, growing at rate $g$ per period, so $\tau_{t}=(1+g)^{t-1} \tau$. Re-doing my initial analysis in this context is 
straightforward, and the resulting equation for the welfare gain from increasing $b$ is:

$$
\frac{d W}{d b} \simeq S\left(L-\frac{\gamma_{1}}{\gamma_{1}-S} \varepsilon_{S b}\right)
$$

This result also follows directly from (4) if I assume $G=0$ and take $\varepsilon_{\bar{Y} b}$ to be the elasticity of the lump-sum tax base $\gamma_{1}-S$. Implementing this formula, I get the results in Table 5 . The values of $\frac{d W}{d b}$ are much smaller, as the optimal values of $b$; if $\frac{\partial S}{\partial a_{1}}=0$ then there is no reason whatsoever to subsidize education (I set $b=0$ as a lower bound).

Table 5: Results from Sufficient Statistics and Extrapolation with no Fiscal Externalities

\begin{tabular}{ccc}
\hline \hline & \multicolumn{2}{c}{$\frac{\hat{\partial} S}{\partial a_{1}}$} \\
\cline { 2 - 3 }$\varepsilon_{S b}$ & 0 & 0.0021 \\
\hline & \multicolumn{2}{c}{ A. Estimate of $\frac{d W}{d b}$ at $b=2$} \\
\cline { 2 - 3 } 0.1 & -0.0407 & 0.0064 \\
0.2 & -0.0814 & -0.0592 \\
\cline { 2 - 3 } 0.1 & \multicolumn{2}{c}{ B. Optimal Student Grants } \\
\cline { 2 - 3 } 0.2 & $\$ 0$ & $\$ 3251$ \\
& & C. Welfare Gains from Moving to Optimum \\
\cline { 2 - 3 } 0.1 & $\$ 295(9.5 \%)$ & $\$ 30(1.0 \%)$ \\
0.2 & $\$ 539(17.4 \%)$ & $\$ 335(10.8 \%)$ \\
\hline
\end{tabular}

The structural approach also follows in the usual way. The results can be found in Table 6, and present conclusions that are similar to those in Table 5, with slightly larger values for $\frac{d W}{d b}$ and optimal grants: the optimal grants are still very small in the absence of fiscal externalities. Therefore, using both approaches, I find that fiscal externalities are important to establishing beneficial effects of significantly increased grants to students; even large liquidity constraints on their own might not be enough to support significant grant increases, and in the baseline case, the optimal policy would involve reducing or even abolishing tuition subsidies in the absence of fiscal externalities. ${ }^{30}$

\subsection{Liquidity Constraints are Second-Order for Policy Analysis}

In section 3, it was already apparent from my numerical results that varying the magnitude of liquidity constraints had relatively little impact on the optimal subsidy; in the baseline case with $\varepsilon_{S b}=0.2$, switching from a zero effect of income on enrollment to the estimate

\footnotetext{
${ }^{30}$ An indirect subsidy from state appropriations may still exist; thus, it is perhaps more appropriate to speak here of reducing the total effective subsidy rather than of abolishing subsidies.
} 
Table 6: Results from Calibration and Simulation with No Fiscal Externalities

\begin{tabular}{ccc}
\hline \hline & \multicolumn{2}{c}{$\frac{\partial S}{\partial a_{1}}$} \\
\cline { 2 - 3 }$\varepsilon_{S b}$ & 0 & 0.0021 \\
\hline \multirow{3}{*}{0.1} & A. Numerical Estimate of $\frac{d W}{d b}$ at $b=2$ \\
\cline { 2 - 3 } 0.2 & -0.0094 & 0.0377 \\
& -0.0473 & -0.0251 \\
\cline { 2 - 3 } 0.1 & \multicolumn{2}{c}{ B. Optimal Student Grants } \\
\cline { 2 - 3 } 0.2 & $\$ 1706$ & $\$ 3275$ \\
& $\$ 1014$ & $\$ 1471$ \\
\cline { 2 - 3 } 0.1 & C. Welfare Gains from Moving to Optimum \\
\cline { 2 - 3 } 0.2 & $\$ 91(0.2 \%)$ & $\$ 97(3.1 \%)$ \\
\hline
\end{tabular}

that Acemoglu and Pischke (2001) called a "large effect" raised optimal subsidies by less than $\$ 300$ per year. In an even more extreme example, subsection 4.1 further proves this point: even eliminating liquidity constraints altogether has little impact on the result, and actually raises the optimal subsidy in the baseline case. However, the analysis in subsection 4.2 demonstrates that the same cannot be said for fiscal externalities; the fiscal motive for subsidizing students is strong, and if somehow it could be eliminated, the case for more generous support for students would almost certainly go with it.

The logic is that, while liquidity constraints may well seem like an important motivation for some form of financial aid, fiscal externalities on their own can justify completely offsetting tuition and possibly providing additional stipends in most cases, by which point any liquidity constraints will have ceased to be a major concern. Therefore, liquidity constraints are of second-order importance when designing college tuition subsidy policy.

\section{$5 \quad$ General Equilibrium Effects}

The findings of the previous section have important implications for future research, as they suggest that research aimed at better estimating the magnitude of externalities from education would be of particular value. Therefore, in this section, I will address two potential sources of variation in the strength of fiscal externalities, both coming from general equilibrium effects of education in the labour market. I begin by looking at how the wage premium may shift with the supply of college graduates, using two different estimates of the elasticity of substitution. Then I consider the possibility of spillovers, or positive externalities of edu- 
cation onto the wages of other workers. I show that, while my conclusion about the limited sensitivity of optimal policy to liquidity constraints is robust to these extensions, general equilibrium effects could significantly alter my results with regards to optimal subsidies, indicating that future research in these areas would be of great benefit to the optimal policy literature.

\subsection{GE Effects on College Wage Premium}

Analysis in papers such as Katz and Murphy (1992) suggests that changes in the supply of college graduates may have significant effects on relative wages. Heckman, Lochner, and Taber (1998a) show that this has consequences for the effectiveness of tuition subsidies: if increased attendance lowers the college wage premium, then grants to students can only induce a small increase in attendance before declines in the wage premium completely offset the increased incentives to attend. Heckman, Lochner, and Taber (1998a) estimate an elasticity of substitution between high school and college graduates of 1.441, and show that this means that the effect of a tuition subsidy on enrollment in general equilibrium is about one-tenth the size of the partial equilibrium effect.

However, this conclusion is sensitive to assumptions about the usage of skill in the economy, as Lee (2005) finds general equilibrium effects of tuition subsidies that are more than 90\% as large as the partial equilibrium values. Also, there is reason to believe that the shortrun effects on relative wages of an increase in supply of college graduates may overstate the long-run effect if increased supply of skills leads to technological change to take advantage of those skills. Acemoglu (1998), Kiley (1999) and Acemoglu (2002) present models in which an increased supply of skilled workers leads to technological adjustment that creates more jobs designed for skilled workers, with the skill premium then increasing over time, possibly above the original level. The magnitude of long-run general equilibrium effects therefore remains an unanswered question, and one that is deserving of further study; in the present analysis I will simply present results corresponding to both the Heckman, Lochner, and Taber (1998a) and Lee (2005) cases.

I begin by assuming a CES production function over high school and college graduates, specifically:

$$
Y_{t}=\zeta_{t}\left(a S_{1 t}^{\kappa}+(1-a) S_{0 t}^{\kappa}\right)^{\frac{1}{\kappa}}
$$

where $S_{1 t}=S$ and $S_{0 t}=1-S$. I assume that wages and the production function are 
specific to the generation in question, i.e. that vintage effects make the human capital of different cohorts perfectly non-substitutable, thereby producing an upper bound on general equilibrium effects. ${ }^{31}$ Therefore the wage of a college graduate is $Y_{1 t}=\frac{\partial Y_{t}}{S_{1 t}}$ and the wage of a high school graduate is $Y_{0 t}=\frac{\partial Y_{t}}{S_{0 t}}$, and $a$ is chosen to make $\frac{Y_{1 t}}{Y_{0 t}}=1.08^{4}$ at baseline. Calibration proceeds in the same way as before, since the only derivative used there is $\frac{d S}{d b}$, which I assume is evaluated at constant wages.

I produce results for two different values of the elasticity of substitution, which can be written as $\frac{1}{1-\kappa}$, namely 1.441 as in Heckman, Lochner, and Taber (1998a), which is a typical value in the literature, and a much higher value of 375 , which generates a ratio of general equilibrium to partial equilibrium effects that is comparable to Lee (2005). ${ }^{32}$ These results are displayed in Tables 7 and 8.

Table 7: Results from Calibration and Simulation with Elasticity of Substitution $=1.441$

\begin{tabular}{|c|c|c|}
\hline \multirow[b]{2}{*}{$\varepsilon_{S b}$} & \multicolumn{2}{|c|}{$\frac{\hat{\partial S}}{\partial a_{1}}$} \\
\hline & 0 & 0.0021 \\
\hline & \multicolumn{2}{|c|}{ A. Numerical Estimate of $\frac{d W}{d b}$ at $b=2$} \\
\hline 0.1 & -0.0567 & 0.0034 \\
\hline \multirow[t]{2}{*}{0.2} & -0.0532 & -0.0245 \\
\hline & \multicolumn{2}{|c|}{ B. Optimal Student Grants } \\
\hline 0.1 & $\$ 315$ & $\$ 2109$ \\
\hline \multirow[t]{2}{*}{0.2} & $\$ 426$ & $\$ 1278$ \\
\hline & \multicolumn{2}{|c|}{ C. Welfare Gains from Moving to Optimum } \\
\hline 0.1 & $\$ 195(6.3 \%)$ & $\$ 1(0.03 \%)$ \\
\hline 0.2 & $\$ 171(5.5 \%)$ & $\$ 35(1.1 \%)$ \\
\hline
\end{tabular}

If high- and low-education workers are not good substitutes for each other, as argued by Heckman, Lochner, and Taber (1998a), then my findings confirm those of the latter paper in that the role of tuition subsidies in increasing enrollment is minimal; even significant liquidity constraints would not lead us to prefer any noticeable increase in subsidies. However, with a much higher elasticity of substitution as in Lee (2005), the results are nearly identical to those from the baseline analysis. The magnitude of these general equilibrium effects, therefore, is

\footnotetext{
${ }^{31}$ That is, I assume that the population share of college graduates adjusts immediately to that of the current generation, rather than allowing for gradual adjustment to a new long-run equilibrium. In this I follow the approach of Heckman, Lochner, and Taber (1998b), who state that short-run general equilibrium effects on enrollment with rational expectations are also very small.

${ }^{32}$ The average of the ratio for men $\left(\frac{1.05}{1.12}\right)$ and for women $\left(\frac{1.52}{1.66}\right)$ in Lee (2005) is 0.9266 ; the average ratio across the four cases displayed in Table 8 is 0.9248 .
} 
Table 8: Results from Calibration and Simulation with Elasticity of Substitution $=375$

\begin{tabular}{ccc}
\hline \hline & \multicolumn{2}{c}{$\frac{\partial S}{\partial a_{1}}$} \\
\cline { 2 - 3 }$\varepsilon_{S b}$ & 0 & 0.0021 \\
\hline & A. Numerical Estimate of $\frac{d W}{d b}$ at $b=2$ \\
\cline { 2 - 3 } 0.1 & 0.1133 & 0.1621 \\
0.2 & 0.3668 & 0.3922 \\
\cline { 2 - 3 } 0.1 & \multicolumn{2}{c}{ B. Optimal Student Grants } \\
\cline { 2 - 3 } 0.2 & $\$ 3879$ & $\$ 4746$ \\
& $\$ 5902$ & $\$ 6211$ \\
\cline { 2 - 3 } 0.1 & C. Welfare Gains from Moving to Optimum \\
\cline { 2 - 3 } 0.2 & $\$ 2824(13.7 \%)$ & $\$ 882(28.4 \%)$ \\
\hline
\end{tabular}

of considerable importance, clearly demonstrating the importance of future work that can shed more light onto this phenomenon, while it remains true that the effect of liquidity constraints on optimal policy is modest.

\subsection{Wage Spillovers}

A number of papers have sought evidence of positive wage spillovers from college education, i.e. a positive externality of education manifesting itself in higher wages for other workers, resulting from off-the-job interactions or some form of social capital. This is not entirely a fiscal externality, as the spillovers have important direct effects on other individuals, but they will also lead to increased tax revenues with important fiscal benefits. Moretti (2004a) and Moretti (2004b) represent two prominent examples that do find significant effects, whereas Ciccone and Peri (2006) do not. Damon and Glewwe (2011) evaluate the literature and conclude that a "very conservative" estimate of this effect is that a one percentage point increase in the population with a bachelor's degree increases average wages by $0.2 \%$ within education groups, with other estimates often in the range of $1 \%$. I will therefore proceed by using this estimate.

This effect can easily be incorporated into the simulation to find a numerical estimate of $\frac{d W}{d b}$, but moving away from $\hat{b}=2$, it does not seem plausible that this spillover would remain at the same level as $S$ increases. Therefore, in Table 9 below I present results where the effect declines with $S$, so that the wage increase per percentage point of attendance is $\frac{\delta}{S^{2}}$, where $\delta=0.002\left(0.388^{2}\right) .{ }^{33}$

\footnotetext{
${ }^{33}$ This implies a spillover that declines from $0.2 \%$ at $S=0.388$ to $0.12 \%$ at $S=0.5$ and to $0.06 \%$ at
} 
Table 9: Results from Calibration and Simulation with Spillovers

\begin{tabular}{ccc}
\hline \hline & \multicolumn{2}{c}{$\frac{\partial \hat{S}}{\partial a_{1}}$} \\
\cline { 2 - 3 }$\varepsilon_{S b}$ & 0 & 0.0021 \\
\hline & A. Numerical Estimate of $\frac{d W}{d b}$ at $b=2$ \\
\cline { 2 - 3 } 0.1 & 1.6665 & 1.7285 \\
0.2 & 3.2238 & 3.2725 \\
\cline { 2 - 3 } 0.1 & \multicolumn{2}{c}{ B. Optimal Student Grants } \\
\cline { 2 - 3 } 0.2 & $\$ 18187$ & $\$ 17920$ \\
& $\$ 15609$ & $\$ 15545$ \\
\cline { 2 - 3 } 0.1 & C. Welfare Gains from Moving to Optimum \\
0.2 & $\$ 74677(1429.7 \%)$ & $\$ 44651(1438.5 \%)$ \\
\hline
\end{tabular}

Even with this "very conservative" assumption about wage spillovers, the welfare gain from increasing student grants is now enormous; a 1\% increase in $b$ to $\$ 2020$ generates an annual economy-wide gain of $\$ 1.81$ billion in the baseline case. Furthermore, even with spillovers that diminish at the rate of $S^{2}$, the optimal grants are very large, higher than the median value of tuition, room and board at public universities of $\$ 13035$ in 2007-08, and the welfare gains are also very large, with a value of $\$ 523.0$ billion in the baseline case, or $3.6 \%$ of GDP. Given the increased spending of $\$ 196.8$ billion per year that such a policy change would imply, the return to investment is $266 \%$. Also, because of the spillovers to uneducated individuals, there is considerable scope for Pareto improvements; in all cases, Pareto gains can be obtained from marginal increases in $b$ up to at least $\$ 10000$, and at the optimum, both high school and college graduates are better off than when $b=2$. Finally, stronger liquidity constraints are actually associated with slightly lower optimal subsidies, as they imply that part of the response of enrollment will disappear as $b$ becomes sufficiently high.

The results for the optimum can only be a rough approximation, given the lack of evidence on how spillovers would change with $S$, but the magnitude of the welfare derivative alone indicates that wage spillovers that might have been considered small in previous work are actually extremely important, indicating a need for further work in this area.

$S=0.7$. 


\section{Conclusion}

In this paper, I have presented a simple model of college education, and performed an analysis of optimal tuition subsidies in the presence of fiscal externalities and liquidity constraints using both a sufficient statistics method and a simple calibration. My results indicate that fiscal externalities on their own provide justification for increased government support for students, as the increased tax base resulting from increased college enrollment produces significant fiscal benefits. The estimated optimal tuition subsidies are relatively large, of a magnitude similar to median tuition at public universities.

Liquidity constraints, however, are of second-order importance for optimal tuition subsidy policy, and the results are robust even to an elimination of liquidity constraints. In contrast, my results indicate that the optimal level of the tuition subsidy is sensitive to the existence of significant general equilibrium effects of tuition subsidies on wages. If effects on relative wages are as severe as those estimated by Heckman, Lochner, and Taber (1998a), then there is no longer a case for significant increases in subsidies. On the other hand, even modest wage spillovers could provide a case for stipends that are considerably larger than median tuition. Thus, further work that models and estimates wage formation in general equilibrium would be especially relevant for the purposes of welfare analysis.

\section{A Liquidity Ratio with Heterogeneous Constraints}

To be as general as possible, let me allow for the possibility that $\eta_{i}$ and $A_{i}$ are jointly distributed according to some bivariate distribution function $F(\eta, A)$. Let me define $S_{A}(A)$ to be the probability of college attendance for an individual with debt limit $A$; this can be written as:

$$
S_{A}(A)=1-F_{\eta \mid A}\left[R_{1} v\left(c_{v}^{0}\right)-u\left(c_{u}(A)\right)-R_{2} v\left(c_{v}^{1}(A)\right) \mid A\right]
$$

where $F_{\eta \mid A}$ represents the conditional cdf. Then the overall probability of college attendance is simply $S=\int_{A} S_{A}(A) f_{A}(A) d A$, where $f_{A}$ is the marginal density of $A$.

Next, observe that:

$$
\begin{gathered}
\frac{\partial S}{\partial b}=\int_{A} \frac{\partial S_{A}(A)}{\partial b} f_{A}(A) d A=\int_{A} f_{\eta \mid A}\left(\eta_{A}^{*} \mid A\right) f_{A}(A) u^{\prime}\left(c_{u}(A)\right) d A \\
\frac{\partial S}{\partial a_{1}}=\int_{A} \frac{\partial S_{A}(A)}{\partial a_{1}} f_{A}(A) d A=\int_{A} f_{\eta \mid A}\left(\eta_{A}^{*} \mid A\right) f_{A}(A)\left[u^{\prime}\left(c_{u}(A)\right)-v^{\prime}\left(c_{v}^{0}\right)\right] d A
\end{gathered}
$$

where $\eta_{A}^{*}$ is the critical value for $A_{i}=A$. Therefore, using the definition of $L$ from the text:

$$
L=\frac{\int_{A} f_{\eta \mid A}\left(\eta_{A}^{*} \mid A\right) f_{A}(A)\left[u^{\prime}\left(c_{u}(A)\right)-v^{\prime}\left(c_{v}^{0}\right)\right] d A}{\int_{A} f_{\eta \mid A}\left(\eta_{A}^{*} \mid A\right) f_{A}(A) v^{\prime}\left(c_{v}^{0}\right) d A} .
$$


Meanwhile, the term I wish to replace is $\frac{E_{1}\left[u^{\prime}\left(c_{u i}\right)\right]-v^{\prime}\left(c_{v}^{0}\right)}{v^{\prime}\left(c_{v}^{0}\right)}$; this is greater or less than $L$ as:

$$
\begin{gathered}
E_{1}\left[u^{\prime}\left(c_{u i}\right)\right] \gtreqless \frac{\int_{A} f_{\eta \mid A}\left(\eta_{A}^{*} \mid A\right) f_{A}(A) u^{\prime}\left(c_{u}(A)\right) d A}{\int_{A} f_{\eta \mid A}\left(\eta_{A}^{*} \mid A\right) f_{A}(A) d A} \\
\frac{\int_{A}\left[1-F_{\eta \mid A}\left(\eta_{A}^{*} \mid A\right)\right] f_{A}(A) u^{\prime}\left(c_{u}(A)\right) d A}{\int_{A}\left[1-F_{\eta \mid A}\left(\eta_{A}^{*} \mid A\right)\right] f_{A}(A) d A} \gtreqless \frac{\int_{A} f_{\eta \mid A}\left(\eta_{A}^{*} \mid A\right) f_{A}(A) u^{\prime}\left(c_{u}(A)\right) d A}{\int_{A} f_{\eta \mid A}\left(\eta_{A}^{*} \mid A\right) f_{A}(A) d A} .
\end{gathered}
$$

If the conditional hazard rate $\frac{f_{\eta \mid A}\left(\eta_{A}^{*} \mid A\right)}{1-F_{\eta \mid A}\left(\eta_{A}^{*} \mid A\right)}$ is constant, these two terms will be equal, and I can safely replace $\frac{E_{1}\left[u^{\prime}\left(c_{u i}\right)\right]-v^{\prime}\left(c_{v}^{0}\right)}{v^{\prime}\left(c_{v}^{0}\right)}$ with $L$ in $(3)$. More generally, let me continue by substituting $h(A)$ for the conditional hazard rate, and let me also write $k(A)=\left[1-F_{\eta \mid A}\left(\eta_{A}^{*} \mid A\right)\right] f_{A}(A)$ to represent the measure of enrollees at a particular value of $A_{i}$; then the comparison becomes:

$$
\begin{gathered}
\frac{\int_{A} k(A) u^{\prime}\left(c_{u}(A)\right) d A}{\int_{A} k(A) d A} \gtreqless \frac{\int_{A} k(A) h(A) u^{\prime}\left(c_{u}(A)\right) d A}{\int_{A} k(A) h(A) d A} \\
\frac{\int_{A} k(A) h(A) d A}{\int_{A} k(A) d A} \frac{\int_{A} k(A) u^{\prime}\left(c_{u}(A)\right) d A}{\int_{A} k(A) d A} \gtreqless \frac{\int_{A} k(A) h(A) u^{\prime}\left(c_{u}(A)\right) d A}{\int_{A} k(A) d A} \\
E_{1}[h(A)] E_{1}\left[u^{\prime}\left(c_{u}(A)\right) \gtreqless E_{1}\left[h(A) u^{\prime}\left(c_{u}(A)\right)\right]\right. \\
0 \gtreqless \operatorname{Cov}_{1}\left[h(A), u^{\prime}\left(c_{u}(A)\right)\right] .
\end{gathered}
$$

Therefore, if the covariance of the hazard and the marginal utility among students is close to zero, it will be a reasonable approximation to insert $L$ into (3). Meanwhile, I will tend to underestimate the liquidity effect if the covariance is negative, which would follow, for instance, if $h(A)$ is increasing in $A$ (given that $u^{\prime}\left(c_{u}(A)\right)$ should be non-increasing in $A$ ).

Given that $\eta_{A}^{*}$ is decreasing in $A$, I would want the hazard to be decreasing in $\eta$, which would be the case for distributions such as the Pareto and the $\chi^{2}$ for degrees of freedom less than 2 (with 2 degrees of freedom, the hazard is constant). However, many other distributions, including the logistic that I use in my calibration, feature an increasing hazard, in which case my overestimate of $L$ would tend to offset the conservative assumptions elsewhere in the model.

\section{B Calculation of $\varepsilon_{\bar{Y} b}$}

First, assuming that the only effects of $b$ on $\bar{Y}$ are from $b$ 's effect on schooling and from the effect of the tax change on earnings $Y_{01}$ and $Y_{11}$, I can write:

$$
\varepsilon_{\bar{Y} b}=\frac{b}{\bar{Y}} \frac{d \bar{Y}}{d b}=\frac{b}{\bar{Y}}\left[\frac{\partial \bar{Y}}{\partial S} \frac{d S}{d b}+\frac{\partial \bar{Y}}{\partial \tau} \frac{d \tau}{d b}\right]
$$

It is clear that $\frac{\partial \bar{Y}}{\partial S}=\gamma_{2} Y_{11}-\gamma_{1} Y_{01}=\left[\gamma_{2}(1.08)^{4}-\gamma_{1}\right] Y_{01}$, and given that I assume that the elasticity of taxable income is 0.4 , I have $\frac{\partial \bar{Y}}{\partial \tau}=-0.4 \frac{\bar{Y}}{1-\tau}$. Using (2) for $\frac{d \tau}{d b}$, the equation for $\varepsilon_{\bar{Y} b}$ becomes:

$$
\varepsilon_{\bar{Y} b}=\left[\gamma_{2}(1.08)^{4}-\gamma_{1}\right] Y_{01} \frac{S}{\bar{Y}} \varepsilon_{S b}-0.4 \frac{S b}{(1-\tau) \bar{Y}}\left[1+\varepsilon_{S b}-\left(1+\frac{G}{S b}\right) \varepsilon_{\bar{Y} b}\right]
$$

and rearranging, I arrive at:

$$
\varepsilon_{\bar{Y} b}=\left[\frac{\left[\gamma_{2}(1.08)^{4}-\gamma_{1}\right] S}{\gamma_{2}(1.08)^{4} S+\gamma_{1}(1-S)}-\frac{0.4 \tau}{1-\tau}\left(1+\frac{G}{S b}\right)^{-1}\right] \frac{1-\tau}{1-1.4 \tau} \varepsilon_{S b}-\frac{0.4 \tau}{1-1.4 \tau}\left(1+\frac{G}{S b}\right)^{-1} .
$$




\section{Sensitivity Analyses}

This section will be devoted to an examination of the robustness of my results. I begin with an analysis of the sensitivity of my results to the coefficient of relative risk-aversion, and then I use the estimates of fiscal costs and benefits from Trostel (2010) to assess the impact on my conclusions of how these fiscal effects are modelled. I also extend the model to consider uncertainty about future incomes, as well as heterogeneity in liquidity constraints and returns to education. The quantitative results are only slightly altered in each case, and the qualitative conclusions remain very similar.

\section{C.1 Increased Risk-Aversion}

My first sensitivity analysis considers how the results change when I specify a coefficient of relative risk-aversion of $\rho=2$ for the employed state. Since I only need to specify this parameter when using the structural method, it will only affect my simulation results. Calibration proceeds as before, and simulation yields the results displayed in Table 10. The optimal values of $b$ and welfare effects are a bit smaller in most cases, but the conclusion of offsetting median tuition continues to hold in the baseline case, and the effects of liquidity constraints remain small.

Table 10: Results from Calibration and Simulation for $\rho=2$

\begin{tabular}{ccc}
\hline \hline & \multicolumn{2}{c}{$\frac{\hat{\partial S}}{\partial a_{1}}$} \\
\cline { 2 - 3 }$\varepsilon_{S b}$ & 0 & 0.0021 \\
\hline \multirow{2}{*}{0.1} & A. Numerical Estimate of $\frac{d W}{d b}$ at $b=2$ \\
\cline { 2 - 3 } 0.2 & 0.1485 & 0.1951 \\
\cline { 2 - 3 } 0.1 & 0.4188 & 0.4409 \\
\cline { 2 - 3 } 0.2 & \multicolumn{2}{c}{ B. Optimal Student Grants } \\
\cline { 2 - 3 } 0.1 & C. Welfare Gains from Moving to Optimum \\
\cline { 2 - 3 } 0.2 & $\$ 536(17.3 \%)$ & $\$ 93407$ \\
\hline
\end{tabular}

\section{C.2 Evidence from Trostel (2010) on Fiscal Effects of Education}

In this subsection, I will test the robustness of my results to a different choice of $\hat{b}$; specifically, I perform my analysis again using the most pessimistic estimates from Trostel (2010), in which he concludes that each year of college costs the government $\$ 17850$ and saves expenditures amounting to $\$ 13950$ in present value. I therefore select $\hat{b}=18$, increasing $e$ to 21.7 to correspond, and I assume that each year of schooling also saves expenditures amounting to $p=14 .{ }^{34}$ This changes the government budget constraint: I now divide $G$ into two components, one exogenous component

\footnotetext{
${ }^{34}$ If instead I set $p=16$ to correspond to the baseline case in which I assume that government appropriations for education are exactly offset by reductions in other expenditures, all results are identical to those in section 3 except that the optimal grants and welfare gains using statistical extrapolations are almost all larger, due to functional form assumptions.
} 
denoted by $G_{1}$, and one component $G_{2}=(1-S) p$ representing the expenditures which can be eliminated with increased schooling. Therefore, the derivative of the budget constraint is:

$$
\frac{d \tau}{d b}=\frac{S}{\bar{Y}}\left[1+\left(\frac{b-p}{b}\right) \varepsilon_{S b}-\left(1+\frac{G}{S b}\right) \varepsilon_{\bar{Y} b}\right]
$$

and inserting this into $\frac{d V}{d b}$, I derive the following variant of (4):

$$
\frac{d W}{d b} \simeq S\left[L-\left(\frac{b-p}{b}\right) \varepsilon_{S b}+\left(1+\frac{G}{S b}\right) \varepsilon_{\bar{Y} b}\right] .
$$

Because the baseline value of $b$ is 9 times larger, the earlier values of $\varepsilon_{S b}=\{0.1,0.2\}$ are now replaced by $\varepsilon_{S b}=\{0.9,1.8\}$. For the optimal grants, let me write them as $\tilde{b}=b-16$ to make them comparable to earlier results; evaluating (6) and using the same statistical extrapolations as before leads to the results displayed in Table 11. The values of $\frac{d W}{d b}$ are smaller now, but the optimal grants are generally larger, as are the welfare gains at the optimum, due to the assumptions involved, particularly that of a constant value of $\varepsilon_{S b}$. The baseline result involves an optimal stipend of over $\$ 3600$ above and beyond the value of tuition, and a welfare gain amounting to $\$ 36.6$ billion; effects of liquidity constraints are again small, and possibly negative.

Table 11: Results from Sufficient Statistics and Extrapolation using (6)

\begin{tabular}{ccc}
\hline \hline & \multicolumn{2}{c}{$\frac{\hat{\partial S}}{\partial a_{1}}$} \\
\cline { 2 - 3 }$\varepsilon_{S b}$ & 0 & 0.0021 \\
\hline \multirow{2}{*}{0.9} & \multicolumn{2}{c}{ A. Estimate of $\frac{d W}{d b}$ at $b=18$} \\
\cline { 2 - 3 } 1.8 & 0.1370 & 0.1841 \\
& 0.3267 & 0.3489 \\
\cline { 2 - 3 } 0.9 & \multicolumn{2}{c}{ B. Optimal Student Grants $\tilde{b}=b-16$} \\
\cline { 2 - 3 } 1.8 & $\$ 7795$ & $\$ 8392$ \\
& & C. Welfare Gains from Moving to Optimum \\
\cline { 2 - 3 } 0.9 & $\$ 1563(5.6 \%)$ & $\$ 2353(8.4 \%)$ \\
1.8 & $\$ 5220(18.7 \%)$ & $\$ 5204(18.6 \%)$ \\
\hline
\end{tabular}

Calibration and simulation follows the same procedure as before, and the results are found in Table 12. In every case, the welfare derivative at baseline is smaller, as are the optimal grants and the welfare gains from moving to the optimum; the optimal grants drop by about $\$ 1000$, and the baseline result no longer involves a subsidy equal to tuition, but still calls for significantly reduced out-of-pocket costs. Once again, stronger liquidity constraints have a modest effect.

\section{C.3 Income Uncertainty}

Next, I consider a case with uncertainty about future incomes. To keep the problem simple, I assume that all uncertainty is resolved after the first period. Thereafter, educated individuals receive either $Y_{1 t H}=(1+g)^{t-1} Y_{11 H}$ in each period or $Y_{1 t L}=(1+g)^{t-1} Y_{11 L}$, each with probability 0.5 , where $Y_{11 H}>Y_{11 L}$ and $\frac{Y_{11 H}+Y_{11 L}}{2}=Y_{11}$. Meanwhile, uneducated workers begin with $Y_{01}$ in the first period, and thereafter receive $Y_{0 t H}=(1+g)^{t-1} Y_{01 H}$ or $Y_{0 t L}=(1+g)^{t-1} Y_{01 L}$, each with probability 0.5 , where $\frac{Y_{01 H}+Y_{01 L}}{2}=Y_{01}$. The corresponding consumption values will be denoted as 
Table 12: Results from Calibration and Simulation for $\hat{b}=18$

\begin{tabular}{|c|c|c|}
\hline \multirow[b]{2}{*}{$\varepsilon_{S b}$} & \multicolumn{2}{|c|}{$\frac{\partial S}{\partial a_{1}}$} \\
\hline & 0 & 0.0021 \\
\hline & \multicolumn{2}{|c|}{ A. Numerical Estimate of $\frac{d W}{d b}$ at $b=18$} \\
\hline 0.9 & 0.0684 & 0.1154 \\
\hline \multirow[t]{2}{*}{1.8} & 0.3094 & 0.3316 \\
\hline & \multicolumn{2}{|c|}{ B. Optimal Student Grants $\tilde{b}=b-16$} \\
\hline 0.9 & $\$ 3127$ & $\$ 3946$ \\
\hline \multirow[t]{2}{*}{1.8} & $\$ 5149$ & $\$ 5425$ \\
\hline & C. Welfare G & Moving to Optimum \\
\hline 0.9 & $\$ 154(0.6 \%)$ & $\$ 448(1.6 \%)$ \\
\hline 1.8 & $\$ 1968(7.0 \%)$ & $\$ 2296(8.2 \%)$ \\
\hline
\end{tabular}

$c_{v H}^{1}$ and $c_{v L}^{1}$ for educated workers and $c_{v H}^{0}$ and $c_{v L}^{0}$ for uneducated workers, with $c_{v 1}^{0}$ representing the consumption of first-period workers.

In deriving $\frac{d W}{d b}$, the only meaningful change will come from the fact that $\frac{\partial V}{\partial \tau}$ takes a different form, specifically:

$\frac{\partial V}{\partial \tau}=-\frac{\gamma_{2}}{2} S\left(v^{\prime}\left(c_{v L}^{1}\right) Y_{11 L}+v^{\prime}\left(c_{v H}^{1}\right) Y_{11 H}\right)-\frac{1-S}{2}\left(v^{\prime}\left(c_{v L}^{0}\right)\left(Y_{01}+\gamma_{2} Y_{01 L}\right)+v^{\prime}\left(c_{v H}^{0}\right)\left(Y_{01}+\gamma_{2} Y_{01 H}\right)\right)$.

However, this equation cannot be used in its current form, and the most reasonable simplification is still $\bar{Y} v^{\prime}\left(c^{*}\right)$, where $\bar{Y}$ remains equal to $S \gamma_{2} Y_{11}+(1-S) \gamma_{1} Y_{01}$, so that (4) holds in this case as well, and the results are unchanged.

I will therefore focus on the structural analysis. The calibration proceeds largely as before, except that $A$ and $\theta$ must be chosen simultaneously to generate consumption choices which match $E\left(c_{v}^{1}\right)=1.26 E\left(c_{v}^{0}\right)$ and $u^{\prime}\left(c_{u}\right)=(\hat{L}+1) v^{\prime}\left(c_{v 1}^{0}\right)$. For the variability of of income, I collect data on the median and interquartile range of income for high school and college graduates from the CPS in the 4th quarter of 2012. Then I consider three cases: one case in which I choose the values of $\left\{Y_{0 L}, Y_{0 H}, Y_{1 H}, Y_{1 L}\right\}$ that produce the same interquartile range, specifically $74.3 \%$ for high school graduates and $81.5 \%$ for college graduates, one case in which I cut the high school IQR in half, and one in which I cut the college IQR in half. The results are displayed in Table 13, and the optimal grants and welfare gains are larger in every case, with small effects of liquidity constraints, though there does not appear to be one unambiguous pattern of results across the three cases. The baseline results feature subsidies equal to median tuition plus about $\$ 1000$ to $\$ 2200$ per year.

\section{C.4 Heterogeneity in Liquidity Constraints and Two-Tier Grants}

In appendix A, I examined how robust the sufficient statistics condition in (4) is to a distribution of debt limits; an alternative examination of the robustness of the results to heterogeneous liquidity constraints can be performed using a structural approach. I allow for two groups, each representing half of the population, ${ }^{35}$ one of which is unconstrained while the other faces a debt limit $A$. I calibrate the model for $\{A, \theta, \mu, \sigma\}$ using the sufficient statistics as averages, and then solve for the

\footnotetext{
${ }^{35}$ Brown, Scholz, and Seshadri (2012) find that approximately half of the children in their sample did not receive post-schooling cash transfers from their parents, which they claim as an indicator for student liquidity constraints.
} 
Table 13: Results from Calibration and Simulation with Uncertain Income

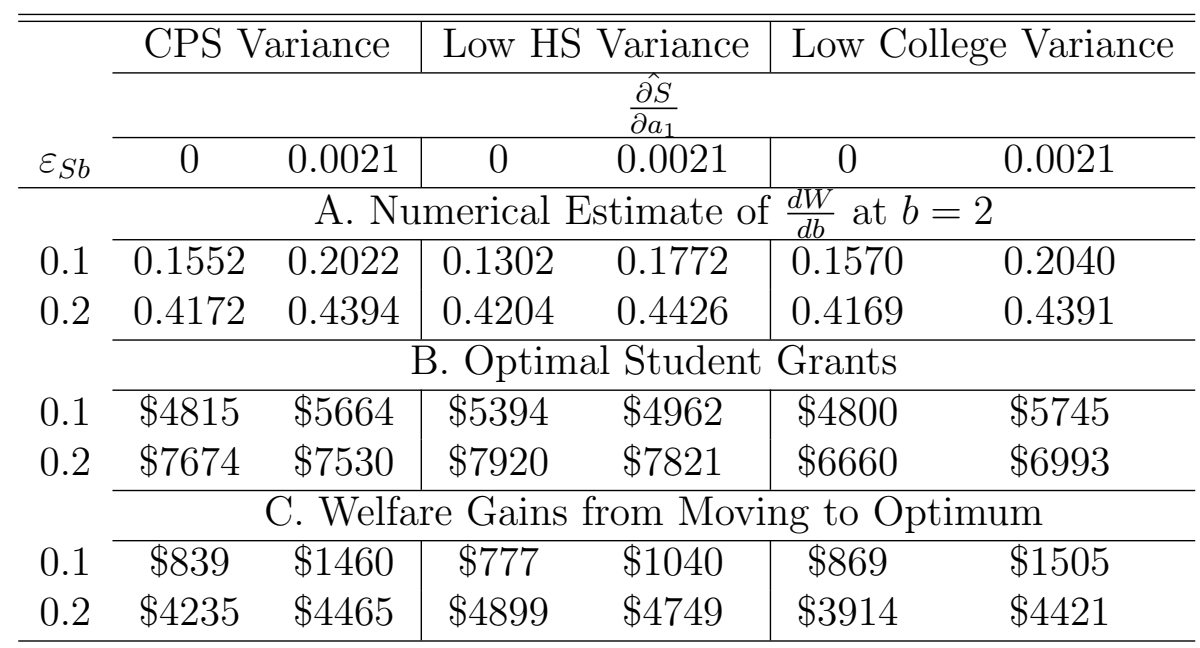

optimal lump-sum student grant, with the results displayed in Table 14 . The values of $\frac{d W}{d b}$ are slightly smaller than in Table 3, which is to be expected because the logistic distribution for $\eta$ has an increasing hazard (see appendix A), but the optimal level of $b$ and the welfare gains are actually higher.

Table 14: Results from Calibration and Simulation with Heterogeneous Liquidity Constraints

\begin{tabular}{ccc}
\hline \hline & \multicolumn{2}{c}{$\frac{\hat{\partial S}}{\partial a_{1}}$} \\
\cline { 2 - 3 }$\varepsilon_{S b}$ & 0 & 0.0021 \\
\hline & A. Numerical Estimate of $\frac{d W}{d b}$ at $b=2$ \\
\cline { 2 - 3 } 0.1 & 0.1221 & 0.1636 \\
0.2 & 0.4161 & 0.4340 \\
\cline { 2 - 3 } 0.1 & \multicolumn{1}{c}{ B. Optimal Student Grants } \\
\cline { 2 - 3 } 0.2 & $\$ 4358$ & $\$ 5112$ \\
& C. Welfare Gains from Moving to Optimum \\
\cline { 2 - 3 } 0.1 & $\$ 575(18.5 \%)$ & $\$ 1012(32.6 \%)$ \\
0.2 & $\$ 3992(128.6 \%)$ & $\$ 4387(141.3 \%)$ \\
\hline
\end{tabular}

With this calibrated model in hand, I can go one step further and consider what policy the government would want to set if they could observe individuals' debt limits; with two types of individuals, the government could introduce a two-tier grant system, with one grant amount $b_{1}$ for the constrained group and another amount $b_{2}$ for unconstrained students. It is straightforward to numerically maximize welfare (still measured as equally-weighted utilitarian social welfare) over the pair $\left(b_{1}, b_{2}\right)$, and the results for this exercise can be found in Table 15. Not surprisingly, it is always optimal to provide more generous aid to the constrained group, but substantial grants to the unconstrained group are still optimal with the standard estimate of $\varepsilon_{S b}=0.2$, as the fiscal externality motive remains strong; in the baseline case with $L=0$, it remains optimal to completely offset tuition, plus an additional stipend of about $\$ 1400$ for the constrained group. The welfare gains over and above those from the lump-sum policy in Table 14 are relatively small in most 
cases, providing further evidence on the limited relevance of liquidity constraints: even a perfectlyinformed government could not improve the outcome much with policies specifically targetting constrained individuals.

Table 15: Results from Calibration and Simulation with Two-Tier Grants

\begin{tabular}{|c|c|c|}
\hline \multirow[b]{2}{*}{$\varepsilon_{S b}$} & \multicolumn{2}{|c|}{$\hat{L}$} \\
\hline & 0 & $\frac{1}{3}$ \\
\hline \multirow{4}{*}{$\begin{array}{l}0.1 \\
0.2\end{array}$} & A. Optimal Two-Tier & tudent Grants $\left(b_{1} / b_{2}\right)$ \\
\hline & $\$ 5475 / \$ 1763$ & $\$ 6773 / \$ 841$ \\
\hline & $\$ 7174 / \$ 5830$ & $\$ 7657 / \$ 5586$ \\
\hline & B. Welfare Gains from & Moving to Optimum \\
\hline 0.1 & $\$ 844(27.2 \%)$ & $\$ 1742(56.1 \%)$ \\
\hline 0.2 & $\$ 4072(131.2 \%)$ & $\$ 4572(147.3 \%)$ \\
\hline
\end{tabular}

\section{C.5 Heterogeneous Returns to Education}

I now investigate how sensitive the results are to allowing for heterogeneous returns to education. I assume that the college wage premium $P$ (where $Y_{11}=P Y_{01}$ ) follows some distribution $G(P)$, and to be precise I use a quadratic approximation to the marginal treatment effect distribution presented in Figure 4 of Carneiro, Heckman, and Vytlacil (2011), and displayed in my Figure 3. I divide the population into 100 equal masses denoted by $j=\{1,2, \ldots, 100\}$, with wage premia equal to $\left\{G^{-1}(0.005), G^{-1}(0.015), \ldots, G^{-1}(0.995)\right\}$, and then I allow for a distribution of $\eta$ for each minipopulation, where $\eta$ is allowed to be correlated with $P$. In particular, I let $\eta_{i j}=\bar{\eta}_{j}+\eta_{i}$, where $\bar{\eta}_{j}$ is deterministic for each $j$ and $\eta_{i}$ comes from a logistic distribution with mean 0 and scale parameter $\sigma$. I specify $\bar{\eta}_{j}=U_{0}-U_{1 j}+z-\mu_{s}\left(\frac{j-1}{j}\right)^{1.2}$, where $U_{1 j}=u\left(c_{u j}\right)+R_{2} v\left(c_{v j}^{1}\right)$, as this generates a pattern of responsiveness to $b$ which is consistent with that found in Carneiro, Heckman, and Vytlacil (2011).

Allowing for a distribution of wage premia makes it important to model the tax system more realistically: I assume that the state and Medicare tax rates do not vary with income, but I use an approximation to the US federal system in 2008 , with a $15 \%$ marginal rate up to $\$ 41500$ and a $25 \%$ rate beyond. To account for the personal exemption of $\$ 3500$ and the standard deduction of $\$ 5450$, as well as the fact that the first $\$ 8025$ of taxable income is only taxed at a $10 \%$ rate, I assume a universal tax refund of $\$ 1743.75$. To avoid discontinuities in the marginal tax schedule, I use a smoothed approximation to the tax rate between $\$ 39000$ and $\$ 44000$, specifically a sine connecting $\tau=0.23$ at $\$ 39000$ to $\tau=0.33$ at $\$ 44000$. I assume that the tax rate threshold moves up with wage growth, and that when taxes need to adjust to balance the budget, the base (state and Medicare) tax rate is the one that moves.

When calibrating, I select values for $\left\{A, \theta, \mu_{s}, \sigma, z\right\}$ in order to match five quantities, three of which are familiar: $E_{1}\left[u^{\prime}\left(c_{u i}\right)\right]=(\hat{L}+1) v^{\prime}\left(c_{v}^{0}\right), \hat{S}=0.388$, and $\varepsilon_{S b}=\{0.1,0.2\}$, although in this case $\varepsilon_{S b}$ is interpreted as a partial derivative. I also choose $z$ to generate a probability of attendance of $95 \%$ for the highest-return group, and I use the fact that college graduates consume $73.9 \%$ of their pre-tax income and high school graduates consume $83.4 \%$ to motivate setting $\frac{\frac{E_{1}\left(c_{v}^{1}\right)}{E_{1}\left(Y_{1}\right)}}{\frac{c_{v}^{0}}{Y_{0}}}=\frac{0.739}{0.834}$.

This leads to the results presented in Table 16. The striking finding is that the welfare derivative at baseline is significantly larger, because the average return to education among those induced to 
Figure 3: College Wage Premium Distribution $G(P)$

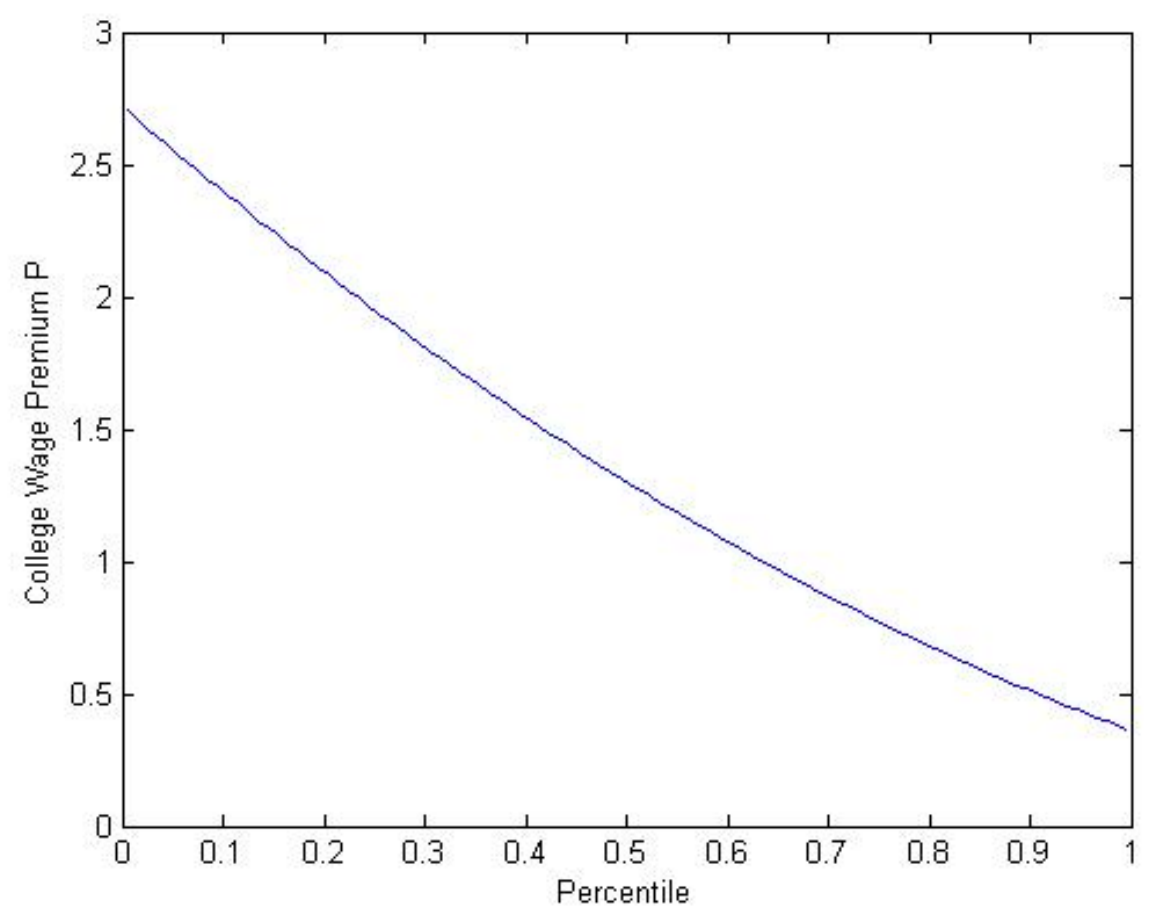

Table 16: Results from Calibration and Simulation with Heterogeneous Returns to Education

\begin{tabular}{ccc}
\hline \hline & \multicolumn{2}{c}{$\hat{L}$} \\
\cline { 2 - 3 }$\varepsilon_{S b}$ & 0 & $\frac{1}{3}$ \\
\hline & A. Numerical Estimate of $\frac{d W}{d b}$ at $b=2$ \\
\cline { 2 - 3 } 0.1 & 1.1593 & 1.2661 \\
0.2 & 2.9816 & 3.0670 \\
\cline { 2 - 3 } 0.1 & \multicolumn{2}{c}{ B. Optimal Student Grants } \\
\cline { 2 - 3 } 0.2 & $\$ 5248$ & $\$ 5669$ \\
& C. Welfare Gains from Moving to Optimum \\
\cline { 2 - 3 } 0.1 & $\$ 7036(226.7 \%)$ & $\$ 8559(275.7 \%)$ \\
0.2 & $\$ 14767(475.7 \%)$ & $\$ 15756(507.6 \%)$ \\
\hline
\end{tabular}

go to school is higher using the estimates from Carneiro, Heckman, and Vytlacil (2011). However, there are diminishing returns to inducing college attendance, because increasingly generous grants induce students with lower monetary returns to go to school; therefore, optimal grants are lower when $\varepsilon_{S b}=0.2$, though they are larger when $\varepsilon_{S b}=0.1$ because the returns to inducing college attendance do not decline as quickly in that case. In the baseline case, if heterogeneous returns of this magnitude do exist, it may no longer be optimal to completely offset tuition, but a significant increase in the generosity of grants is still indicated, and the welfare gains are significantly larger than before, amounting to $\$ 103.4$ billion per year.

This analysis provides us with a sense of how heterogeneity in returns can affect the results, but 
naturally has more of a "black box" character than the baseline analysis. The current method is not as well suited to answering questions about how financial aid could be better targetted at students on the margin of attending college or from groups with high returns, and therefore future work using structural models with observed and unobserved heterogeneity could be useful in providing answers to such questions.

\section{References}

Acemoglu, D. (1998): "Why Do New Technologies Complement Skills? Directed Technical Change and Wage Inequality," Quarterly Journal of Economics, 113(4), 1055-1089.

- (2002): "Directed Technical Change," Review of Economics Studies, 69(4), 781-809.

Acemoglu, D., And J.-S. Pischke (2001): "Changes in the Wage Structure, Family Income, and Children's Education," European Economic Review, 45(4-6), 890-904.

Akyol, A., And K. Athreya (2005): "Risky Higher Education and Subsidies," Journal of Economic Dynamics and Control, 29(6), 979-1023.

Baily, M. N. (1978): "Some Aspects of Optimal Unemployment Insurance," Journal of Public Economics, 10(3), 379-402.

Belley, P., M. Frenette, And L. Lochner (2011): "Post-Secondary Attendance by Parental Income in the U.S. and Canada: What Role for Financial Aid Policy," Working Paper no. 17218, NBER, Cambridge, MA.

Belley, P., And L. Lochner (2007): "The Changing Role of Family Income and Ability in Determining Educational Achievement," Journal of Human Capital, 1(1), 37-89.

Bohacek, R., And M. Kapicka (2008): "Optimal Human Capital Policies," Journal of Monetary Economics, 55(1), 1-16.

Bovenberg, A. L., And B. Jacobs (2005): "Redistribution and Education Subsidies are Siamese Twins," Journal of Public Economics, 89(11-12), 2005-2035.

Braun, C. (2010): "Optimal Taxation of Education with an Initial Endowment of Human Capital," Paper no. 210, Ruhr Economic Papers.

Brown, M., J. K. Scholz, And A. Seshadri (2012): "A New Test of Borrowing Constraints for Education," Review of Economic Studies, 79(2), 511-538.

Cameron, S. V., And J. J. Heckman (2001): "The Dynamics of Educational Attainment for Black, Hispanic, and White Males," Journal of Political Economy, 109(3), 455-499.

Cameron, S. V., And C. TABer (2004): "Estimation of Educational Borrowing Constraints Using Returns to Schooling," Journal of Political Economy, 112(1, part 1), 132-182.

CARD, D. (1999): "The Causal Effect of Education on Earnings," in Handbook of Labor Economics, ed. by O. Ashenfelter, and D. Card, vol. 3A, Elsevier, pp. 1801-1863. 
Carneiro, P., J. J. Heckman, and E. Vytlacil (2010): "Evaluating Marginal Policy Changes and the Average Effect of Treatment for Individuals at the Margin," Econometrica, 78(1), 377394.

(2011): "Estimating Marginal Returns to Education," American Economic Review, 101(6), $2754-2781$.

Caucutt, E. M., and K. B. Kumar (2005): "Higher Education Subsidies and Heterogeneity: A Dynamic Analysis," Journal of Economic Dynamics and Control, 27(8), 1459-1502.

Chetтy, R. (2008): "Moral Hazard versus Liquidity and Optimal Unemployment Insurance," Journal of Political Economy, 116(2), 173-234.

- (2009): "Sufficient Statistics for Welfare Analysis: A Bridge Between Structural and Reduced-Form Methods," Annual Review of Economics, 1, 451-487.

Ciccone, A., And G. Peri (2006): "Identifying Human-Capital Externalities: Theory with Applications," Review of Economic Studies, 73(2), 381-412.

Coelli, M. B. (2011): "Parental Job Loss and the Education Enrollment of Youth," Labour Economics, 18(1), 25-35.

Courant, P. N., M. McPherson, And A. M. Resch (2006): "The Public Role in Higher Education," National Tax Journal, 59(2), 291-318.

Cunha, F., J. J. Heckman, L. Lochner, and D. V. Masterov (2006): "Interpreting the Evidence on Life Cycle Skill Formation," in Handbook of the Economics of Education, ed. by E. A. Hanushek, and F. Welsh, vol. 1, Elsevier, pp. 697-812.

Cutler, D. M., And L. F. Katz (1991): "Macroeconomic Performance and the Disadvantaged," Brookings Papers on Economic Activity, 2(2), 1-74.

Damon, A., And P. Glewwe (2011): "Valuing the Benefits of the Education Provided by Public Universities: A Case Study of Minnesota," Economics of Education Review, 30(6), 1242-1261.

Deming, D., And S. Dynarski (2009): "Into College, Out of Poverty? Policies to Increase the Postsecondary Attainment of the Poor," Working Paper no. 15387, NBER, Cambridge, MA.

Dynarski, S. (2008): "Building the Stock of College-Educated Labor," Journal of Human Resources, 43(3), 576-610.

Epple, D., R. Romano, and H. Sieg (2006): "Admission, Tuition, and Financial Aid Policies in the Market for Higher Education," Econometrica, 74(4), 885-928.

Gruber, J., And E. SAez (2002): "The Elasticity of Taxable Income: Evidence and Implications," Journal of Public Economics, 84(1), 1-32.

Heckman, J. J., L. Lochner, And C. Taber (1998a): "Explaining Rising Wage Inequality: Explorations with a Dynamic General Equilibrium Model of Labor Earnings with Heterogeneous Agents," Review of Economic Dynamics, 1(1), 1-58. 
(1998b): "General-Equilibrium Treatment Effects: A Study of Tuition Policy," American Economic Review, 88(2), 381-386.

Heckman, J. J., L. Lochner, And P. E. Todd (2006): "Earnings Functions, Rates of Return and Treatment Effects: The Mincer Equation and Beyond," in Handbook of the Economics of Education, ed. by E. A. Hanushek, and F. Welsh, vol. 1, Elsevier, pp. 307-458.

Johnson, M. T. (2012): "Borrowing Constraints, College Enrollment, and Delayed Entry," Working Paper No. 2011-006, Human Capital and Economic Opportunity Working Group, University of Chicago.

Kane, T. J. (1999): The Price of Admission: Rethinking How Americans Pay for College. Brookings Institution Press (with Russell Sage Foundation), Washington, D.C.

(2006): "Public Intervention in Post-Secondary Education," in Handbook of the Economics of Education, ed. by E. A. Hanushek, and F. Welsh, vol. 2, Elsevier, pp. 1369-1401.

Katz, L. F., And K. M. Murphy (1992): "Changes in Relative Wages, 1963-1987: Supply and Demand Factors," Quarterly Journal of Economics, 107(1), 35-78.

Keane, M. P., And K. I. Wolpin (2001): "The Effect of Parental Transfers and Borrowing Constraints on Educational Attainment," International Economic Review, 42(4), 1051-1103.

Kiley, M. T. (1999): "The Supply of Skilled Labour and Skill-Biased Technological Progress," Economic Journal, 109(458), 708-724.

LaWson, N. (2013): "Fiscal Externalities and Optimal Unemployment Insurance," Working Paper No. 2013-57, Aix-Marseille School of Economics.

— (2014): "Social Program Substitution and Optimal Policy," Unpublished Paper, AixMarseille School of Economics.

LeE, D. (2005): "An Estimable Dynamic General Equilibrium Model of Work, Schooling, and Occupational Choice," International Economic Review, 46(1), 1-34.

Levin, H. M., And C. E. Rouse (January 25, 2012): "The True Cost of High School Dropouts," http://www.nytimes.com/2012/01/26/opinion/the-true-cost-of-high-school-dropouts.html, New York Times.

Lochner, L., and A. Monge-Naranjo (2012): "Credit Constraints in Education," Annual Review of Economics, 4, 225-256.

Lochner, L. J., And A. Monge-Naranjo (2011): "The Nature of Credit Constraints and Human Capital," American Economic Review, 101(6), 2487-2529.

Lovenheim, M. F. (2011): "The Effect of Liquid Housing Wealth on College Enrollment," Journal of Labor Economics, 29(4), 741-771. 
McPherson, M. S., And M. O. Schapiro (2006): "US Higher Education Finance," in Handbook of the Economics of Education, ed. by E. A. Hanushek, and F. Welsh, vol. 2, Elsevier, pp. 14031434.

Moretti, E. (2004a): "Estimating the Social Return to Higher Education: Evidence from Longitudinal and Repeated Cross-Section Data," Journal of Econometrics, 121(1-2), 175-212.

(2004b): "Workers' Education, Spillovers, and Productivity: Evidence from Plant-Level Production Functions," American Economic Review, 94(3), 656-690.

NCES (2011): "National Center for Education Statistics," http://nced.ed.gov/.

Richter, W. F. (2009): "Taxing Education in Ramsey's Tradition," Journal of Public Economics, 93(11-12), 1254-1260.

Richter, W. F., And C. Braun (2010): "Efficient Subsidization of Human Capital Accumulation with Overlapping Generations and Endogenous Growth," Working Paper no. 2982, CESifo.

Saez, E. (2002): "Optimal Income Transfer Programs: Intensive versus Extensive Labor Supply Responses," Quarterly Journal of Economics, 117(3), 1039-1073.

Trostel, P. A. (1993): "The Effect of Taxation on Human Capital," Journal of Political Economy, 101(2), 327-350.

_ (1996): "Should Education be Subsidized?," Public Finance Review, 24(1), 3-24.

(2010): "The Fiscal Impacts of College Attainment," Research in Higher Education, 51(3), $220-247$. 